\title{
Review on Time-Integrated Overheating Evaluation Methods for Residential Buildings in Temperate Climates of Europe
}

\author{
R. Rahif*, D. Amaripadath, S. Attia \\ Sustainable Building Design Lab, Dept. UEE, Faculty of Applied Sciences, Université de Liege, Belgium
}

\section{A R T I C L E I N F O}

\section{Article history:}

Received 25 May 2021

Revised 31 August 2021

Accepted 11 September 2021

Available online 17 September 2021

\section{Keywords:}

Thermal comfort

EPBD

Long-term comfort

International standards

Thermal discomfort

Chronic overheating

\begin{abstract}
A B S T R A C T
Overheating exposure over time can lead to discomfort, productivity reduction, and health issues for the occupants in buildings. The time-integrated overheating evaluation methods are introduced to describe, in a synthetic way, the extent of overheating over a span of time and predict the uncomfortable phenomena. This paper reviews the time-integrated overheating evaluation methods that are applicable to residential buildings in temperate climates of Europe. We critically analyze the methods found in (i) 11 international standards, namely, EN 15251 (2006), EN 16798 (2019), ISO 7730 (2004), ISO 17772 (2017-2018), ASHRAE 55 (2017), ASHRAE 55 (2020), CIBSE Guide A (2006), CIBSE TM52 (2013), CIBSE Guide A (2015), CIBSE TM59 (2017), and Passive House (2015), (ii) five national building codes based on the Energy Performance of Building Directive (EPBD) in Belgium, France, Germany, the UK, and the Netherlands, and (iii) two studies in the scientific literature. For each method, we present the thermal comfort models along with the time-integrated overheating indices and criteria. The methods are analyzed according to some key measures in order to identify their scope, strength, and limitations. We found that most standards recommend the static comfort models for air-conditioned buildings and the adaptive comfort models for non-air-conditioned ones. We also found a promising method based on three indices, namely, Indoor Overheating Degree (IOD), Ambient Warmness Degree (AWD), and overheating escalation factor $\left(\alpha_{\mathrm{IOD} / \mathrm{AWD}}\right)$ that allows for a multi-zonal and climate change-sensitive overheating assessment. Finally, some guidance is provided for practice and future developments.
\end{abstract}

(c) 2021 Elsevier B.V. All rights reserved.

\section{Contents}

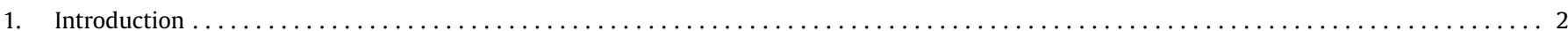

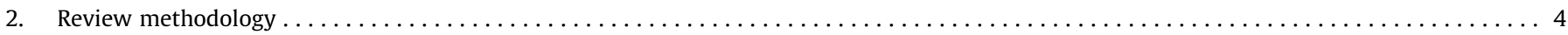

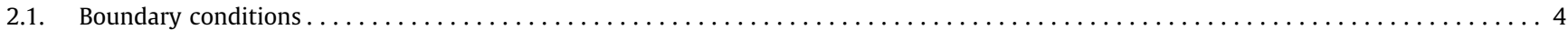

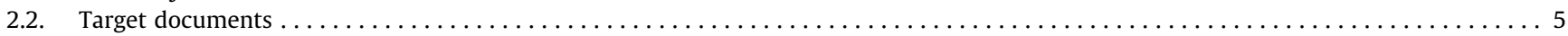

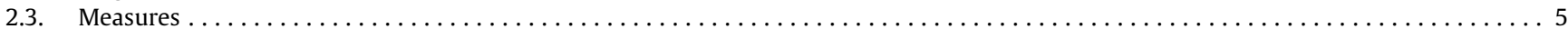

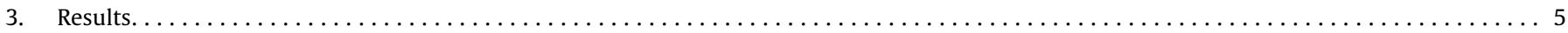

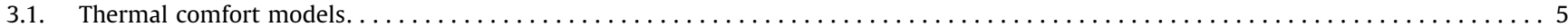

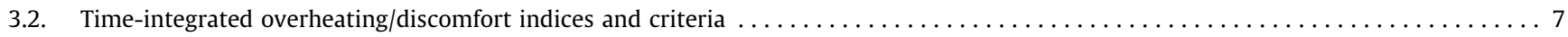

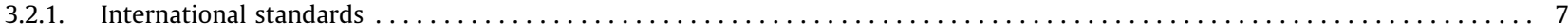

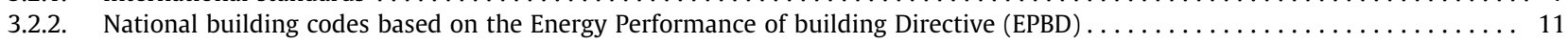

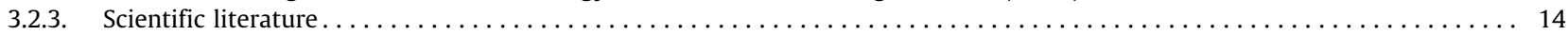

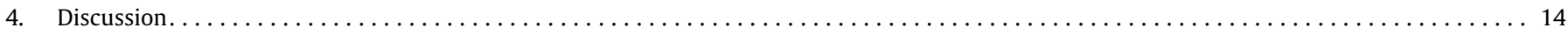

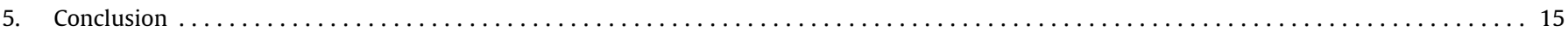

\footnotetext{
* Corresponding author.

E-mail address: ramin.rahif@uliege.be (R. Rahif).
} 


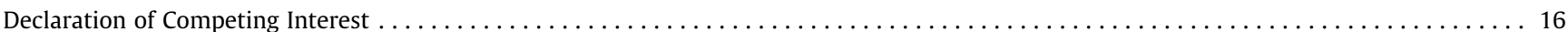

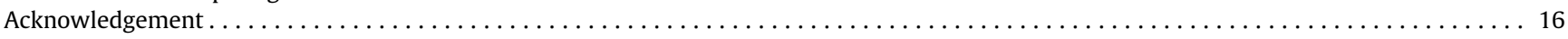

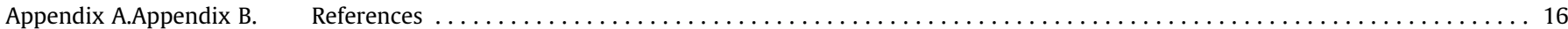

\section{Introduction}

During the last two decades, extremely hot outdoor conditions have become more intense and frequent in temperate climates of Europe. In summer 2003, the outdoor air temperatures of $35^{\circ} \mathrm{C}$, $37{ }^{\circ} \mathrm{C}, 38.5{ }^{\circ} \mathrm{C}$, and $40.2{ }^{\circ} \mathrm{C}$ were recorded in the Netherlands, France, the UK, and Germany, respectively [1-4]. Royal Meteorological Institute (RMI) of Belgium reported that the Hechtel-Eksel municipality experienced 51 consecutive days with the outdoor air temperature above $25{ }^{\circ} \mathrm{C}$, and a maximum air temperature of $38.8{ }^{\circ} \mathrm{C}$ is recorded in the summer of 2018 .

Unfortunately, the situation will worsen since the European Environment Agency (EEA) predicts an increase in the annual average air temperature between 1.0 and $2.5{ }^{\circ} \mathrm{C}$ by $2021-2050$ and between 2.5 and $4{ }^{\circ} \mathrm{C}$ by $2071-2100$ over Europe. It is expected that Europe's sweltering heatwave in 2003 will become typical weather by the middle of the 21st century [5]. In addition, the Urban Heat Island (UHI) effect that is recognized in more than 400 cities around the world will be exacerbated by climate change $[6,7]$. The UHI effect, defined as the "relatively atmospheric warmth of urban areas compared to surrounding countryside" [8], is predicted to increase the land air temperature in Europe by $2.68^{\circ} \mathrm{C}$ (December to February) and $5.06{ }^{\circ} \mathrm{C}$ (June to August) in urban areas by 2080-2099 [9]. Such warming outdoor conditions will increase the risk of overheating in indoor environments where people spend most of the time [10].

Overheating in residential buildings has been reported in many temperate regions across Europe [11-15]. High indoor temperatures affect the occupant's health, comfort, and productivity where in severe cases can lead to illness and death [16,17]. According to Housing Health and Safety Rating System (HHSRS) in the UK, the indoor temperature exceeding the maximum threshold of $25{ }^{\circ} \mathrm{C}$ can lead to an increase in strokes and mortality [18]. In total, over 35,000 people died in Europe during the summer 2003 heatwave [19], in which 14,729 deaths reported in France [20], 2139 in England and Wales [21], up to 2200 in the Netherlands [1], 7295 in Germany [22], and 1175 in Belgium [23]. To avoid such issues, there is a need for proper definition and criteria for indoor overheating to be considered in the building designs.

A number of methods are introduced for assessing the human thermal response to the surrounding environment in the literature [24]. They aim at describing the human thermal perception from an environment where an individual or a group of people is exposed. In the last twenty years, a new group of methods are proposed for assessing the comfort over a span of time in buildings, which are termed long-term comfort evaluation methods [25,26], chronic overheating evaluation methods [27], or time-integrated comfort evaluation methods [28]. They aim at evaluating the comfort qualities of a building over time and considering all the building zones [29]. The majority of these methods were developed to assess the overheating discomfort, and some of them deal with overheating and overcooling discomfort at the same time, and only a few of them deal with overcooling discomfort [29,30]. Most of the time-integrated comfort evaluation methods have two key decisions in common, the choice of thermal comfort model and the selection of time-integrated discomfort index. Previous research exists by reviewing the existing thermal comfort models and the time-integrated discomfort indices.
Among the reviews on thermal comfort models, Taleghani et al. [31] chronologically reviewed the static and the adaptive comfort models with a detailed analysis of the adaptive comfort models in ASHRAE 55 (2010), EN 15251, and ISSO 74 (2004) (in the Netherlands) standards. It was found that the main difference of the adaptive comfort models relies on the choice of outdoor reference temperature, the extend of acceptable temperature ranges, and databases related to the field studies. Khovalyg et al. [32] extensively reviewed EN 15251, ISO 17772, EN 16798, ISO 7730, ASHRAE 55 (2017), GB/T 50785 (in China), ISHRAE 10,001 (in India), SS 553, and SS 554 (in Singapore) standards, questioning the applicability of their comfort models on regional scales. Carlucci et al. [33] reviewed the adaptive comfort models in ASHRAE 55, EN 15251, EN16798, ISSO 74 (in the Netherlands), and GB/T 50785 standards. Carlucci et al. [33] also revealed that the difference in the choice of outdoor reference temperature is the primary source of discrepancy in deriving the adaptive comfort models. Cheng et al. [34] reviewed the thermoregulatory models for the human body by distinguishing between the psychological models and physiological models. They numerically assessed the UC Berkeley thermal comfort model (UCB) and ISO 14505 thermal comfort model using a detailed Computational Fluid Dynamics (CFD) analysis. They found that the coupling of the UCB model with CFD is complex, hindering its widespread. On the other hand, the ISO 14505 model is more sensitive in warm environments and less sensitive in cold environments, questioning the reliability of the model. The overview of thermal comfort models and indicators is also presented in [24,35-39]. The focus of the above reviews was mainly on investigating the existing models for thermal comfort.

Despite the numerous studies on thermal comfort models, a limited number of documents reviewed the time-integrated discomfort indices. Carlucci et al. [29] systematically reviewed 15 indices, classifying them into four homogenous families (i.e., percentage indices, cumulative indices, risk indices, and averaging indices). Carlucci [40] quantitatively evaluated 16 timeintegrated discomfort indices focusing on summer overheating in 54 variants of an office building. It was found that different indices would identify different variants as the optimal case. The gap recognition is then performed through the sensitivity analysis by varying the calculation periods in the time-integrated discomfort indices. Finally, the Long-term Percentage of Dissatisfied (LPD) index is proposed, which is a symmetric and comfort modelbased discomfort index. Zero Carbon Hub (a non-profit organization to implement zero energy homes policy in the UK) published an evidence review for overheating risk assessment in buildings in 2015 [41]. It covers the methodologies in the Standard Assessment Procedure (SAP), CIBSE Guide A (2006), CIBSE Guide A (2015), CIBSE TM52, Passive House, BB 101, and Part L2A of UK government's building regulations. Also, the UK National HouseBuilding Council (NHBC) provided a report by studying the overheating definitions in several guidelines and regulatory documents in the UK [42]. The two former studies (i.e., $[29,40]$ ) are outdated since most standards are superseded and new methods are introduced in the literature and the two latter reports (i.e., [41,42]) are local and focused on the methods mainly implemented in the UK. To overcome the limitations of the above studies, by extending our scope to temperate regions in Europe, we explore the longlasting standards in addition to those that were not reviewed 
Table 1

Summary of reviews on thermal comfort models and overheating evaluation methods.

\begin{tabular}{|c|c|c|c|c|c|}
\hline Author & Ref. & Year & Journal/Institution & Thermal comfort models & Overheating evaluation methods \\
\hline Roaf et al. & [39] & 2010 & Architectural Science Review & $\boldsymbol{\nu}$ & \\
\hline Van hoof et al. & [35] & 2010 & Frontiers in Bioscience & 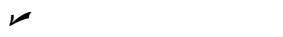 & \\
\hline Carlucci and Pagliano & [29] & 2012 & Energy and Buildings & 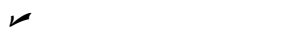 & レ \\
\hline NHBC & [42] & 2012 & NHBC & 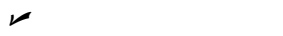 & $\boldsymbol{V}$ \\
\hline Cheng et al. & [34] & 2012 & Building and Environment & 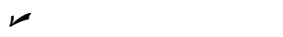 & \\
\hline Halawa and Van Hoof & [36] & 2012 & Energy and Buildings & 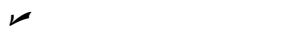 & \\
\hline Taleghani et al. & [31] & 2013 & Renewable and Sustainable Energy Reviews & 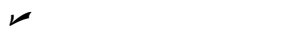 & \\
\hline Carlucci & {$[40]$} & 2013 & Springer & $\boldsymbol{\nu}$ & $\boldsymbol{}$ \\
\hline Yang et al. & [37] & 2014 & Applied Energy & 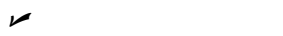 & \\
\hline Zero Carbon Hub & [41] & 2015 & Zero Carbon Hub & 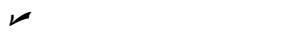 & レ \\
\hline Enescu & {$[24]$} & 2017 & Renewable and Sustainable Energy Reviews & レ & \\
\hline Carlucci et al. & [33] & 2018 & Building and Environment & 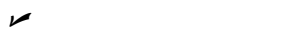 & \\
\hline Khovalyg et al. & {$[32]$} & 2020 & Energy and Buildings & レ & \\
\hline Zhao et al. & [38] & 2021 & Energy and Built Environment & 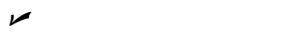 & \\
\hline
\end{tabular}

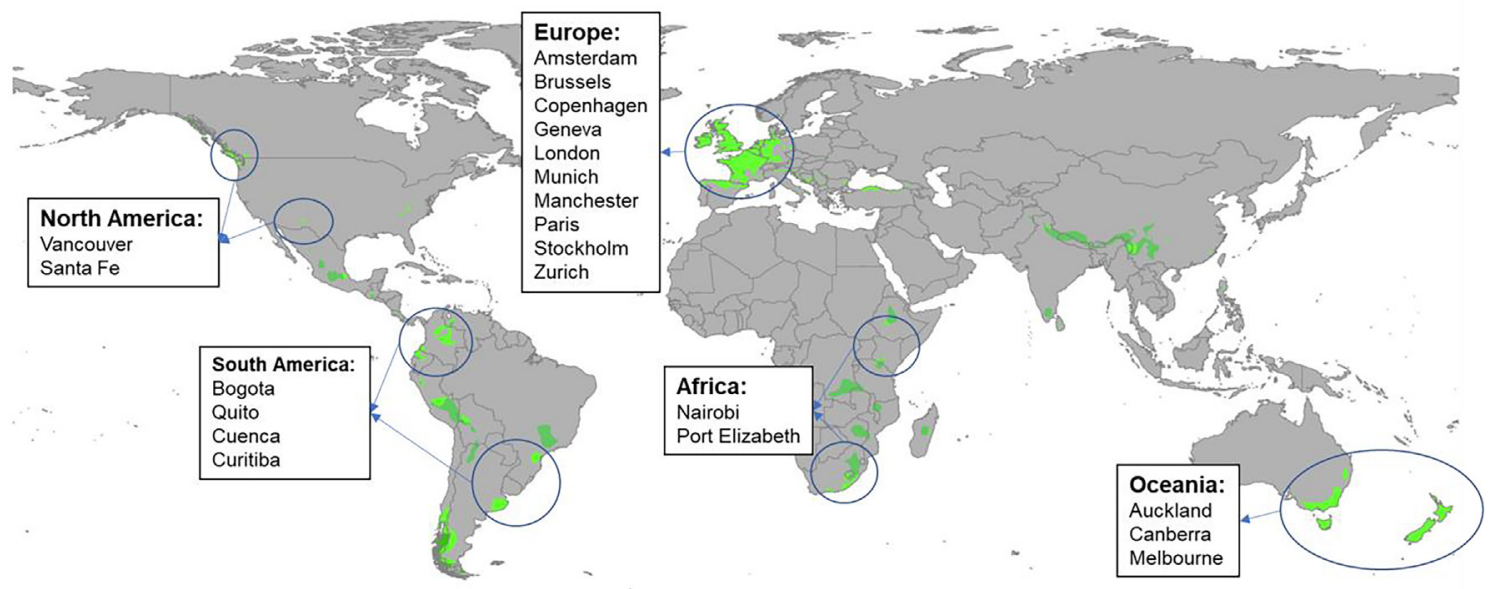

Fig. 1. Cities with Temperate oceanic climate $(\mathrm{Cfb})$ worldwide.

before such as EN 16798, ISO 17772, ASHRAE (2020), CIBSE TM59, and five national codes based on the Energy Performance of Building Directive (EPBD) in Belgium, France, Germany, the UK, and the Netherlands as well as two state-of-the-art methods in the literature [14,43]. Table 1 provides a list of review documents (published after 2010) on thermal comfort models and overheating evaluation methods.

In general, there is a substantial need for a comprehensive review (i.e., thermal comfort models, indices, and criteria) of the time-integrated discomfort evaluation methods focusing on overheating discomfort (we refer to as "time-integrated overheating evaluation methods"). Therefore, as members of the International Energy Agency (IEA) EBC Annex 80 - "Resilient cooling of buildings" project, we initiated this research to address the abovementioned knowledge gap. This paper provides a valuable contribution to the new body of knowledge from an international perspective. Our paper provides insights for overheating assessments in temperate oceanic climate $(\mathrm{Cfb})$ according to Köppen climate classification. Such climate is particularly dominant in Western Europe such as in Brussels that had 2381 Heating Degree Days (HDD) and 38 Cooling Degree Days (CDD) in 2018 [44]. As can be seen in Fig. 1, in addition to many European cities, there are major cities like Auckland, Bogotá, Nairobi, Vancouver, and Santa Fe with similar climate in other regions around the world. Therefore, our study will be useful to improve the understanding of overheating and allow the comparison of overheating evaluation methods globally. We should mention that provisions are required to the generalizability of the results to hot climates.
The main objectives of this paper are, (i) identifying the thermal comfort models suggested for the buildings with and without airconditioning and (ii) exploring the time-integrated overheating indices and criteria. This paper attempts to respond to the following research questions:

1) What are the thermal comfort models suggested in the standards for the buildings with and without air-conditioning?

2) What are the indices suggested to calculate the timeintegrated overheating in residential buildings?

3) What are the threshold values and criteria to limit overheating in buildings?

Our review critically analyzes 95 recent and long-standing documents, including 11 international standards, namely, EN 15251, EN 16798, ISO 7730, ISO 17772, ASHRAE 55 (2017), ASHRAE 55 (2020), CIBSE Guide A (2006), CIBSE TM52, CIBSE Guide A (2015), CIBSE TM59, and Passive House (see Appendix A). We also review five national building codes based on the Energy Performance of Building Directive (EPBD) in Belgium, France, Germany, the UK, and the Netherlands. We highlight the main differences between the new and old versions of the standards. This paper is the first of its kind that focused on the overheating calculation methods specific for residential buildings in temperate climates and thoroughly examined the EPBD regulations. More importantly, we addressed new measures in addition to those in Carlucci et al. [29], such as all hours or occupied hours in a time span, normalization to occupied hours, short-term criteria, and long-term criteria. Our 
extensive review summarizes the vast body of standards and literature in a brief, informative, and content-rich document that allows the comparison of the most critical thermal comfort models and time-integrated overheating indices.

This paper provides strong support for decision-making for building professionals and designers to assess indoor overheating during the early design stages. Implementing the findings may yield comfort benefits in the buildings. The study outcomes also provide practical recommendations for policymakers to improve the regional and national overheating evaluation methods towards climate change proof residential buildings. The paper is structured as follows. Section 2 presents the review methodology including the boundary conditions, target documents, and measures. Section 3 describes the results of the review on the time-integrated overheating evaluation methods including thermal comfort models (Section 3.1) followed by analyzing overheating/discomfort indices and criteria in international standards (Section 3.2.1), national building codes based on the EPBD (Section 3.2.2) and scientific literature (Section 3.2.3). Section 4 discusses the key findings and Section 5 concludes the paper.

\section{Review methodology}

This paper performs a review of the time-integrated overheating evaluation methods. As shown in Fig. 2, towards providing a thorough and in-depth review, we narrow our scope by setting boundary conditions on the building type and the climate. Based on the boundary conditions, we then select the target documents to be reviewed. Finally, the review is conducted by applying some existing and newly defined evaluation measures.

\subsection{Boundary conditions}

As the first boundary condition, we restrict our focus on the methods that are specified for residential buildings. It is since, (i) the majority of European heterogeneous building stock is composed of residential buildings; the share of residential buildings is between 60 and $89 \%$ over the Member States and the UK according to the European Union (EU) buildings Factsheet, (ii) people spend most of their time at homes, in particular elderly people who are more vulnerable to overheating exposure [42], and (iii) the overheating during the sleeping time at homes was reported as a major risk to the public health $[41,45]$.

Another boundary condition is that we focus on the methods proposed for temperate climates. In temperate climates, the focus of building thermal design is mainly on preserving the heat during the winter. Such a design concept prevents the dissipation of internal heat loads in buildings and makes them more vulnerable to overheating issues during the hot summertime [27,46,47]. Therefore, we decided to condemn the policy, legislative, and scientific drivers of overheating in temperate climates as one of the high-risk areas and provide recommendations for future improvements.

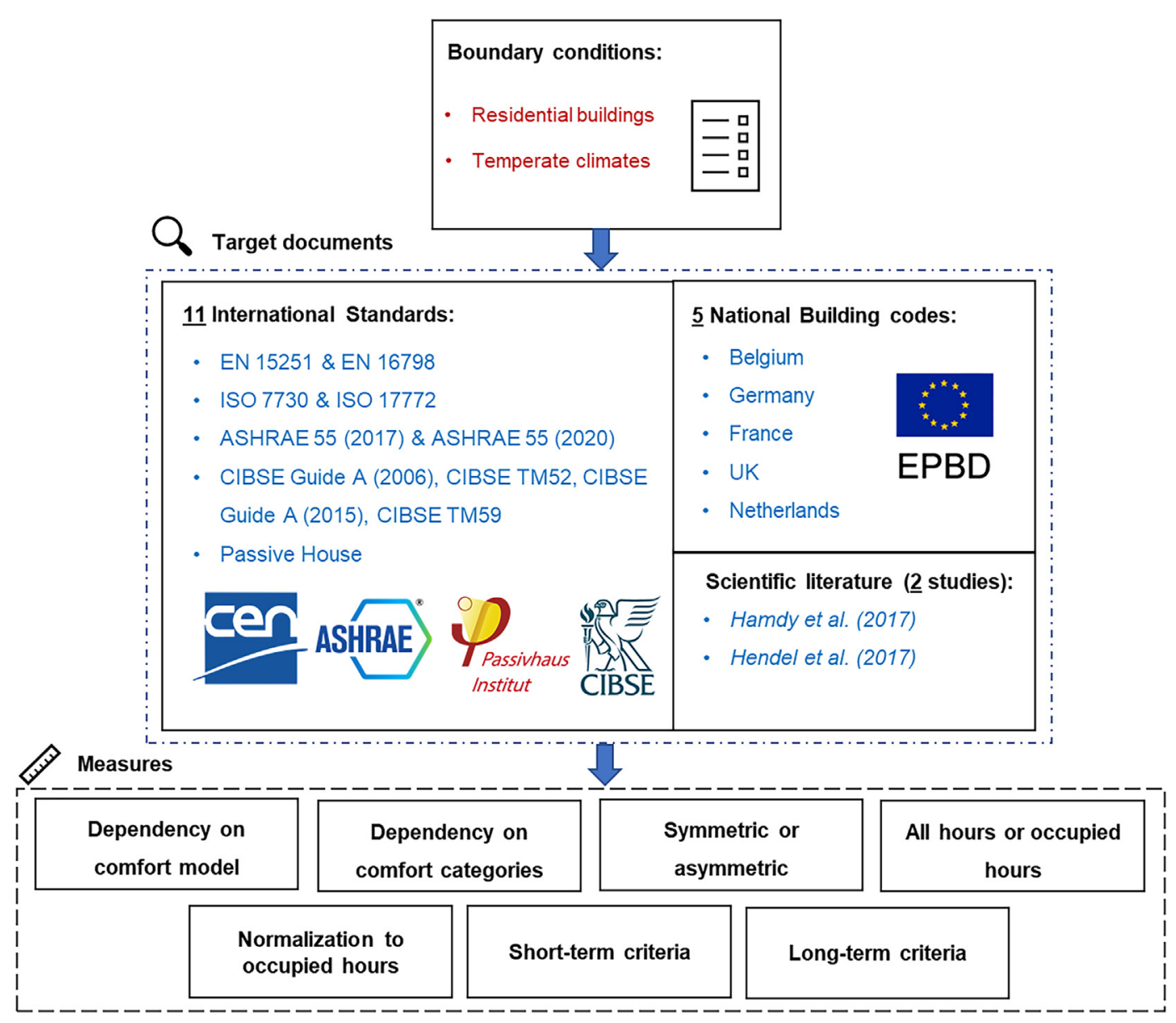

Fig. 2. Study Conceptual Framework (SCF). 


\subsection{Target documents}

The target documents in this paper can be divided into, international standards, EPBD regulatory documents, and scientific literature. For the international standards, we select EN 15251, EN 16798, ISO 7730, ISO 17772, ASHRAE 55 (2017), ASHRAE 55 (2020), CIBSE Guide A (2006), CIBSE TM52, CIBSE Guide A (2015), CIBSE TM59, and Passive House standards. These mostly cited standards [14,48-56] are extensively included within the building construction and renovation policies in temperate climates of Europe. Afterwards, we review the EPBD regulatory documents in Belgium, France, Germany, the UK, and the Netherlands. These five countries form the largest portion of the temperate regions in Europe and together entail $47 \%$ of the total population and $30 \%$ of the total area considering the EU and the UK $[44,57,58]$. The EPBD regulations are obligatory and thus play a main role in defining the energy efficiency and thermal comfort in buildings at the European level. Finally, we select two state-of-the-art methods found in the literature $[14,43]$. For this aim, we set two inclusion criteria: (i) introduced and implemented in residential buildings and (ii) applied and validated for temperate climates in Europe. We exclude the methods in the literature that are previously reviewed by Carlucci et al. [29] or aimed at quantifying the instant overheating phenomena. Our aim is not to provide an extensive review of the methods introduced in the scientific literature, but we intend to take the initiative and provide the basis for future studies in this context. We should also mention that there is no strict limitation on the publication period for the additional documents that form the references of this paper, but priority has been given to recent publications to address the state-of-the-art research.

\subsection{Measures}

The review is carried out by describing the thermal comfort models for air-conditioned and non-air-conditioned buildings along with a critical analysis of the time-integrated overheating indices and criteria (i.e., threshold values). A previous study by Carlucci et al. [29] defined some measures such as dependency on a comfort model, dependency on comfort categories, symmetric/asymmetric, and inclusion/exclusion of comfort thresholds. We further elaborate on those terms and add some new measures including all hours or occupied hours in a time span, normalization to occupied hours, short-term criteria, and long-term criteria. Therefore, this study analyzes the time-integrated overheating evaluation methods based on the following measures,

- Dependency on comfort model: this measure shows that whether the method is dependent on a comfort model. If yes, which of the static and adaptive comfort models are implemented.

- Dependency on comfort categories: this measure shows whether the underlying thermal comfort model of a method relies on comfort categories. Dependency on comfort categories generates discontinuity at the boundaries of the categories and results in different values for overheating if the category changes.

- Symmetric or asymmetric: the symmetric methods combine the overheating and overcooling discomfort in a single value, whereas the asymmetric methods only consider overheating discomfort. The symmetric methods do not imply whether the building is unable to suppress overheating or overcooling discomfort.

- All hours or occupied hours in a time span: this measure shows whether the method considers all hours or only the occupied hours during a specific time period. The inclusion of unoccupied hours in the calculations raises the uncertainty by including the needless effect of comfort conditions where there is no one in the building.

- Normalization to occupied hours: we assess if the index of a method is normalized to the occupied hours. The normalized indices allow the comparison of the buildings with different occupancy profiles.

- Short-term criteria: short-term criteria are threshold values on an hourly, daily, or weekly basis to limit the overheating during the heatwave events.

- Long-term criteria: long-term criteria are threshold values to limit the extensive overheating during monthly, seasonal, or annual periods.

\section{Results}

\subsection{Thermal comfort models}

The evaluation of overheating risks in buildings requires the determination of an appropriate thermal comfort model. The thermal comfort in buildings can be divided into two major models: (a) static and (b) adaptive.

The static comfort models in the comfort standards are mainly based on Fanger's widely accepted PMV/PPD model ( $P M V=$ Predicted Mean Vote and PPD = Predicted Percentage Dissatisfied) developed in the $1970 \mathrm{~s}$ where six major parameters (air temperature, radiant temperature, relative humidity, metabolic rate, air velocity, and clothing factor) intervene. Those parameters were estimated or measured to evaluate the thermal sensation of the human body in a thermally symmetrical environment while calculating the $P M V$ index.

The static comfort models suggested in the $P M V / P P D$ ranges in EN, ISO, ASHRAE, and CIBSE standards are listed in Table 2. The EN and ISO standards provide the $P M V / P P D$ ranges in different categories reflecting the level of occupant expectation and the indoor environmental quality (see Appendix B), whereas ASHRAE (for the static model) and CIBSE standards do not categorize the thermal environments or as CIBSE TM52 refer to a single category.

Since it is difficult to measure the PMV accurately due to high uncertainty in measuring and predicting all comfort parameters, in particular clothing factor and metabolic rate, some standards translate the PMV/PPD ranges into the operative temperature scales with some assumptions. As listed in Table 3, EN 15251, EN 16798, ISO 17772, and CIBSE TM52 (following EN 15251) translate the $P M V / P P D$ ranges into the operative temperature scales with assumptions on relative humidity $(=50 \%$ for EN 15251 , $=40 \%$ and $=60 \%$ for heating and cooling seasons in EN 16,798 and ISO 17772 , respectively), air velocity $(<0.1 \mathrm{~m} / \mathrm{s})$, metabolic rate $(1.2$ met), and clothing factor ( 0.5 clo for summer and 1 clo for winter). Following the same suit, CIBSE Guide A (2006) prescribes the translated operative temperature scales (for $|\mathrm{PMV}|<0,25$ ) considering the clothing factor between 0.25 and 1.2 clo, metabolic rate between 0.9 and 1.8 met, relative humidity $(=50 \%)$, and air velocity $(<0.15 \mathrm{~m} / \mathrm{s})$ over different zones. It is also recommended that the operative temperature ranges can be extended by $1{ }^{\circ} \mathrm{C}$ at each end if a PMV of \pm 0.5 is acceptable. CIBSE Guide A (2015), however, translates the range of $|\mathrm{PMV}|<0,5$ into the operative temperature scales by assumptions on clothing factor between 0.5 and 1.2 clo, metabolic rate between 0.9 and 1.5 met, relative humidity (=50\%), and air velocity $(<0.15 \mathrm{~m} / \mathrm{s})$ over different zones. It also allows fluctuations up to $1{ }^{\circ} \mathrm{C}$ at the boundaries. The translated operative temperature thresholds are associated with boundary conditions, therefore are not applicable to the spaces where: (i) the air velocity threshold is violated by the operation of ceiling fan etc., (ii) the relative humidity exceeds the threshold value by humidifying activities such as cooking in the kitchen or drying 
Table 2

The PMV/PPD static comfort limits in EN, ISO, ASHRAE, and CIBSE. The presented limits are suggested for residential buildings.

\begin{tabular}{|c|c|c|c|}
\hline Standard & Operation type* & Category & $P P D[\%] \& P M V[-]$ \\
\hline \multirow[t]{4}{*}{ EN 15,251 (2007) } & \multirow[t]{4}{*}{ Mechanically heated and cooled } & I & $P P D \%<6,-0.2<P M V<+0.2$ \\
\hline & & II & $P P D \%<10,-0.5<P M V<+0.5$ \\
\hline & & III & $P P D \%<15,-0.7<P M V<+0.7$ \\
\hline & & IV & $P P D \%>15, P M V<-0.7$ orPMV $>+0.7$ \\
\hline \multirow[t]{4}{*}{ EN 16798 (2019) \& ISO 17772 (2017) } & \multirow{4}{*}{ Mechanically heated and cooled } & $\mathrm{I}$ & $P P D \%<6,-0.2<P M V<+0.2$ \\
\hline & & II & $P P D \%<10,-0.5<P M V<+0.5$ \\
\hline & & III & $P P D \%<15,-0.7<P M V<+0.7$ \\
\hline & & IV & $P P D \%<25,-1.0<P M V<+1.0$ \\
\hline \multirow[t]{3}{*}{ ISO $7730(2005)$} & \multirow[t]{3}{*}{ All } & I & $P P D \%<6,-0.2<P M V<+0.2$ \\
\hline & & II & $P P D \%<10,-0.5<P M V<+0.5$ \\
\hline & & III & $P P D \%<15,-0.7<P M V<+0.7$ \\
\hline ASHRAE 55 (2017) \& ASHRAE 55 (2020) & All & - & $P P D \%<10,-0.5<P M V<+0.5$ \\
\hline CIBSE Guide A (2006) & Air-conditioned & - & $\begin{array}{l}P P D \%<10,-0.25<P M V<+0.25 P P D \% \\
<10,-0.5<P M V<+0.5 \text { (if acceptable) }\end{array}$ \\
\hline CIBSE TM52 & $\begin{array}{l}\text { Mechanically conditioned and } \\
\text { naturally conditioned }\end{array}$ & II (EN 15251) & $P P D \%<10,-0.5<P M V<+0.5$ \\
\hline CIBSE Guide A (2015) & Air-conditioned & - & $P P D \%<10,-0.5<P M V<+0.5$ \\
\hline
\end{tabular}

*the terminology of each standard is used to name the operation type.

Table 3

The fixed maximum temperature limits in EN, ISO, CIBSE, and Passive House standards. The presented limits are suggested for residential buildings

\begin{tabular}{|c|c|c|c|}
\hline Standard & Operation type* & Zone/category & $\begin{array}{l}\text { Maximum operative } \\
\text { temperature }\left[{ }^{\circ} \mathrm{C}\right]\end{array}$ \\
\hline \multirow[t]{3}{*}{ EN $15251(2007)$} & \multirow[t]{3}{*}{ Mechanically heated and cooled } & Living spaces (bedrooms, living rooms, kitchens, etc.)/I & 25.5 \\
\hline & & Living spaces (bedrooms, living rooms, kitchens, etc.)/II & 26 \\
\hline & & Living spaces (bedrooms, living rooms, kitchens, etc.)/III & 27 \\
\hline \multirow{4}{*}{$\begin{array}{l}\text { EN } 16798(2019) \& \\
\quad \text { ISO } 17772(2017)\end{array}$} & \multirow[t]{4}{*}{ Mechanically heated and cooled } & Living spaces (bedrooms, living rooms, kitchens, etc.)/I & 25.5 \\
\hline & & Living spaces (bedrooms, living rooms, kitchens, etc.)/II & 26 \\
\hline & & Living spaces (bedrooms, living rooms, kitchens, etc.)/III & 27 \\
\hline & & Living spaces (bedrooms, living rooms, kitchens, etc.)/IV & 28 \\
\hline \multirow[t]{4}{*}{ CIBSE Guide A (2006) } & \multirow[t]{2}{*}{ Air-conditioned } & Living rooms, bedrooms, halls, stairs, landings & $\begin{array}{l}25\left(+1^{\circ} \mathrm{C} \text { if } \mathrm{PMV}=0.5 \text { is }\right. \\
\text { acceptable })\end{array}$ \\
\hline & & Kitchen, toilets & $\begin{array}{l}23\left(+1^{\circ} \mathrm{C} \text { if } \mathrm{PMV}=0.5 \text { is }\right. \\
\text { acceptable })\end{array}$ \\
\hline & \multirow[t]{2}{*}{ Free-running } & Living room & 28 \\
\hline & & Bedrooms & 26 \\
\hline CIBSE TM52 & $\begin{array}{l}\text { Mechanically conditioned and naturally } \\
\text { conditioned }\end{array}$ & All/II (EN 15251) & 26 \\
\hline \multirow[t]{2}{*}{ CIBSE Guide A (2015) } & Air-conditioned & $\begin{array}{l}\text { Bathrooms, bedrooms, halls, stairs, landings, kitchen, toilet/II } \\
\text { (EN 15251) }\end{array}$ & $26\left(+1^{\circ} \mathrm{C}\right)$ \\
\hline & Free-running & Bedrooms & 26 \\
\hline \multirow[t]{2}{*}{ CIBSE TM59 } & Mechanically ventilated & All & 26 \\
\hline & Naturally ventilated & Bedrooms & 26 \\
\hline Passive House & $\begin{array}{l}\text { Without active cooling or with passive } \\
\text { cooling }\end{array}$ & All zones & 25 \\
\hline
\end{tabular}

*the terminology of each standard is used to name the operation type.

the clothes inside, and (iii) occupants have activities or clothing that are out-of-range considering the assumptions on metabolic rate and clothing factor.

Differently, some standards provide the static comfort model by proposing fixed temperature thresholds. As indicated in Table 3, CIBSE Guide A (2006) specifies a threshold value denoted as "benchmark peak temperature" for free-running buildings which is $3{ }^{\circ} \mathrm{C}$ higher than the summer comfort temperature. It defines $25{ }^{\circ} \mathrm{C}$ as the summer comfort temperature in the living room at which few people feel uncomfortable. For bedrooms, however, it assigns the summer comfort temperature of $23{ }^{\circ} \mathrm{C}$ since sleep may be impaired above $24{ }^{\circ} \mathrm{C}$. Accordingly, the prescribed benchmark peak temperature is $28{ }^{\circ} \mathrm{C}$ for the living room and $26{ }^{\circ} \mathrm{C}$ for the bedrooms. CIBSE Guide A (2015) and CIBSE TM59 also commonly suggest $26{ }^{\circ} \mathrm{C}$ for the bedrooms in naturally ventilated buildings. The Passive House standard sets a maximum threshold value of $25^{\circ} \mathrm{C}$ for all living areas in buildings without active cooling or with passive cooling. In the case of fixed temperature thresholds, the effect of other comfort parameters such as relative humidity, clothing factor, metabolic rate, and air velocity is totally neglected in defining comfort.

The adaptive comfort model has been developed during the last twenty years based on a group of field studies taken in real buildings to represent the actual conditions. The adaptive comfort theory accepts that the occupants can adapt to the surrounding thermal environment because of the behavioural, physiological, and psychological actions. Therefore, it suggests reaching a temperature that is positively correlated to a reference outdoor air temperature. And not anymore, a unique and ideal temperature.

To derive the reference outdoor air temperature, EN and ISO standards recommend the "exponentially weighted running mean outdoor temperature" $\left(\mathrm{T}_{\mathrm{rmo}}\right)$. The $\mathrm{T}_{\mathrm{rmo}}\left[\mathrm{A}^{\circ} \mathrm{C}\right]$ can be calculated by, 
Table 4

The adaptive comfort boundaries in EN, ISO, ASHRAE, and CIBSE.

\begin{tabular}{|c|c|c|c|c|c|}
\hline Standard & Operation type* & Category or acceptability & Upper limit $\left[{ }^{\circ} \mathrm{C}\right]$ & Lower limit $\left[{ }^{\circ} \mathrm{C}\right]$ & $\begin{array}{l}\mathrm{T}_{\text {rmo }} \text { or } \mathrm{T}_{\text {pmo }} \text { applicability } \\
\text { range }\left[{ }^{\circ} \mathrm{C}\right]\end{array}$ \\
\hline \multirow[t]{3}{*}{ EN 15251 (2007) } & \multirow[t]{3}{*}{ Without mechanical heating and cooling } & I & $0.33 T_{r m o}+18.8+2$ & $0.33 T_{r m o}+18.8-2$ & $10-30$ \\
\hline & & II & $0.33 T_{r m o}+18.8+3$ & $0.33 T_{r m o}+18.8-3$ & $10-30$ \\
\hline & & III & $0.33 T_{r m o}+18.8+4$ & $0.33 T_{r m o}+18.8-4$ & $10-30$ \\
\hline \multirow{3}{*}{$\begin{array}{l}\text { EN } 16798 \text { (2019) \& } \\
\quad \text { ISO } 17772(2017)\end{array}$} & \multirow[t]{3}{*}{ Without mechanical heating and cooling } & $\mathrm{I}$ & $0.33 T_{r m o}+18.8+2$ & $0.33 T_{r m o}+18.8-3$ & $10-30$ \\
\hline & & II & $0.33 T_{r m o}+18.8+3$ & $0.33 T_{r m o}+18.8-4$ & $10-30$ \\
\hline & & III & $0.33 T_{r m o}+18.8+4$ & $0.33 T_{r m o}+18.8-5$ & $10-30$ \\
\hline \multirow[t]{2}{*}{ ASHRAE 55 (2017) } & \multirow[t]{2}{*}{ Naturally conditioned } & 80\% Acceptability & $0.31 T_{p m o}+21.3$ & $0.31 T_{p m o}+14.3$ & $10-33.5$ \\
\hline & & 90\% Acceptability & $0.31 T_{p m o}+20.3$ & $0.31 T_{\text {pmo }}+15.3$ & $10-33.5$ \\
\hline CIBSE TM52 & Free-running & II (EN 15251) & $0.33 T_{r m o}+18.8+3$ & $0.33 T_{r m o}+18.8-3$ & $10-30$ \\
\hline $\begin{array}{l}\text { CIBSE Guide A (2015) \& } \\
\text { CIBSE TM59 }\end{array}$ & Naturally ventilated & II (EN 15251) & $0.33 T_{r m o}+18.8+3$ & $0.33 T_{r m o}+18.8-3$ & $10-30$ \\
\hline
\end{tabular}

*the terminology of each standard is used to name the operation type.

$T_{r m o}=(1-\alpha) \cdot\left\{T_{e d-1}+\alpha T_{e d-2}+\alpha^{2} T_{e d-3+\cdots}\right\}$

$$
\begin{aligned}
T_{r m o}= & 1 / 3.8 .\left\{T_{e d-1}+0.8 T_{e d-2}+0.6 T_{e d-3+} 0.5 T_{e d-4}\right. \\
& \left.+0.4 T_{e d-5}+0.3 T_{e d-6}+0.2 T_{e d-7}\right\}
\end{aligned}
$$

Where $\alpha$ is the weighting factor between 0 and 1 (recommended value is 0.8$), T_{\text {ed- } i}$ is the daily mean outdoor air temperature for ith previous day $\left[{ }^{\circ} \mathrm{C}\right]$. ASHRAE 55, however, introduces the "prevailing mean outdoor air temperature" $\left(\mathrm{T}_{\mathrm{pmo}}\right)$ as the reference outdoor air temperature. The $T_{p m o}\left[{ }^{\circ} \mathrm{C}\right]$ is the arithmetic mean of the mean daily outdoor air temperature of all sequential days (no less than seven and no more than 30 days). ASHRAE 55 also permits the use of the weighting method (see Equation (1)) in a way that the weight applied to a day is between 0.6 and 0.9 of that applied to the subsequent day. The formulas to derive the adaptive comfort ranges based on the reference outdoor air temperature and corresponding applicable ranges are summarized in Table 4.

Similar to the static model, EN 15251, EN 16798, and ISO 17772 standards provide category-based adaptive temperature ranges for buildings without mechanical heating and cooling systems. There are some differences in defining the adaptive thermal comfort in EN 15251 compared to EN 16798 and ISO 17772. First, in EN 15251 , it is allowable to install mechanical cooling systems; nevertheless, they should not be in operation. EN 15251 also allows mechanical ventilation, which provides unconditioned air during the summer as well as other low-energy technologies such as shutters, night ventilation, fans, etc. However, this information is excluded in EN 16798 and ISO 17772. Second, the metabolic rate of nearly sedentary activity (1-1.3 met) is assumed in EN 15251, while the metabolic rate of sedentary activity (1.2 met) is assumed in EN 16798 and ISO 17772. Third, EN 16798 and ISO 17772 has a more extensive range of adaptive comfort boundaries since the lower temperature limits are $1{ }^{\circ} \mathrm{C}$ below the equivalent temperature limits in EN 15251.

ASHRAE 55 (2017) and ASHRAE 55 (2020) recommend the adaptive comfort model (see Table 4) for naturally ventilated buildings in two applicability ranges (see Appendix B). However, there are two changes between both versions: (i) ASHRAE 55 (2020) allows for the installation of a mechanical cooling system as long as the system is not in operation which is not permitted in ASHRAE 55 (2017) and (ii) the range of metabolic rate assumption is extended from 1.0 to 1.3 met in ASHRAE 55 (2017) to 1.01.5 met in ASHRAE 55 (2020). The main strength of the ASHRAE 55 standard is its regular revisions and updates (every 3-4 years during the last decade) reflecting the new results from the field studies contributing to the accuracy of its adaptive comfort model [59].
CIBSE TM52, CIBSE Guide A (2015) (not for bedrooms), and CIBSE TM59 (not for bedrooms) commonly adopt Category II of the adaptive comfort model in EN 15251 for free-running and naturally ventilated buildings. It should be mentioned that the ISO 7730, CIBSE Guide A (2006), and Passive House standards do not contain or refer to any adaptive comfort model.

\subsection{Time-integrated overheating/discomfort indices and criteria}

\subsubsection{International standards}

3.2.1.1. EN 15251 and EN 16798. Identical time-integrated discomfort indices are established in EN 15251 (Annex F) and EN 16798 (Annex D of Part 2). Three indices are defined, namely Percentage of Occupied hours Outside the Range $\left(\% P O h O R_{E N}\right)$, Degree hours $\left(D h_{E N}\right)$, and PPD weighted (PPDw).

The \%POhOR ${ }_{E N}$ index shows the percentage of occupied hours when the $P M V$ or indoor operative temperature is outside the comfort ranges related to the selected comfort category. It is thus applicable to both static and adaptive comfort models (see Section 3.1). The \%POhOR $R_{E N}$ can be calculated using a binary weighting factor $\left(\mathrm{wf}_{\mathrm{i}}\right)$ that is zero during the time within the comfort ranges and is one during the out-of-range conditions. It is a straightforward index that shows the frequency of discomfort, however, (i) it does not quantify the intensity of discomfort, (ii) it is category-based, it introduces discontinuities at the boundaries of categories that do not correlate to the physics and physiology [29], and (iii) it is symmetric without distinguishing between the overheating and overcooling discomfort.

Provisions are made to restrict the short-term and long-term overheating by defining acceptable deviation thresholds for the \% $P_{O h O R_{E N}}$ index during weekly, monthly, and annual periods. EN 15251 recommends the acceptable deviation of $3 \%$ (5\%) based on working hours (total hours) during daily, weekly, monthly, and yearly periods. Whereas EN $16798-2$ suggests $20 \%$ (50\% as a strict criterion) weekly, $12 \%$ (25\% as a strict criterion) monthly and $3 \%$ (6\% as a strict criterion) annual acceptable deviations during the occupied hours. The latter sets criteria for how long short-term and long-term consecutive periods of out-of-range temperatures can be accepted.

The $D h_{E N}$ index quantifies the time in which the indoor operative temperature exceeds the specified comfort range weighted by a factor $\left(w f_{i}\right)$. The $w_{i}$ is a module of the difference between the indoor operative temperature and the lower or upper limit of the comfort range. To calculate the $D h_{E N}$, If the comfort ranges are specified in terms of $P M V$, the ranges should be translated into operative temperature scales by assumptions on clothing factor, metabolic rate, relative humidity, and air velocity. Both static and adaptive comfort models are applicable (see Section 3.1). The $D h_{E N}$ is an asymmetric 
Table 5

Summary of overheating/discomfort evaluation methods in EN, ISO, ASHRAE, CIBSE, and Passive House standards.

\begin{tabular}{|c|c|c|c|c|c|c|c|c|c|}
\hline \multirow[t]{2}{*}{ Standard } & \multirow[t]{2}{*}{ Index } & \multirow[t]{2}{*}{ Equation } & \multicolumn{7}{|l|}{ Measures } \\
\hline & & & $\begin{array}{l}\text { Static (S) / } \\
\text { Adaptive } \\
\text { (A) }\end{array}$ & $\begin{array}{l}\text { Category- } \\
\text { based }\end{array}$ & $\begin{array}{l}\text { Symmetric (S) / } \\
\text { Asymmetric (A) }\end{array}$ & $\begin{array}{l}\text { All hours }(A) / \\
\text { occupied } \\
\text { hours }(0)\end{array}$ & $\begin{array}{l}\text { Normalized } \\
\text { to occupied } \\
\text { hours }\end{array}$ & $\begin{array}{l}\text { Short- } \\
\text { term } \\
\text { criterion }\end{array}$ & $\begin{array}{l}\text { Long- } \\
\text { term } \\
\text { criterion }\end{array}$ \\
\hline \multirow[t]{4}{*}{$\begin{array}{l}\text { EN 15251\&EN } \\
\quad 16798 \& I S O 17772\end{array}$} & $\begin{array}{l}\text { Percentage of } \\
\text { Occupied hours } \\
\text { Outside the Range }(\% \\
\left.\text { POhOR }_{E N} \text { I ISO 17772,op }\right)\end{array}$ & 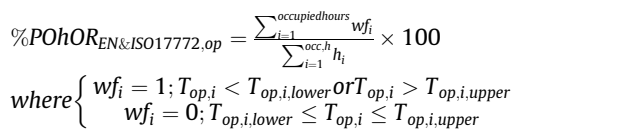 & $S \& A$ & $r$ & $S$ & $o$ & $r$ & $\begin{array}{l}\text { V(not } \\
\text { in EN } \\
15251)\end{array}$ & $r$ \\
\hline & $\begin{array}{l}\text { Percentage of } \\
\text { Occupied hours } \\
\text { Outside the Range }(\% \\
\text { POhOR } \\
\text { PMV })\end{array}$ & 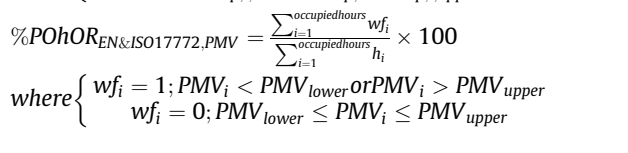 & $S$ & $\nu$ & $S$ & 0 & $r$ & $\begin{array}{l}\text { V(not } \\
\text { in EN } \\
15251)\end{array}$ & $r$ \\
\hline & $\begin{array}{l}\text { Degree hours*( }\left(D h_{E N} \&\right. \\
\text { Iso 17772,overh })\end{array}$ & $\begin{array}{l}D h_{\text {EN\&ISO17772,overh }}=\sum_{i=1}^{o c c u p i e d h o u r s}\left(w f_{i} \times h_{i}\right) \\
\text { where }\left\{\begin{array}{c}w f_{i}=T_{o p, i}-T_{o p, i, u p p e r} ; T_{o p, i}>T_{o p, i, u p p e r} \\
w f_{i}=0 ; T_{o p, i} \leq T_{i, u p p e r}\end{array}\right.\end{array}$ & $S \& A$ & $r$ & A & $o$ & & & \\
\hline & $\begin{array}{l}\text { Weighted PPD* } \\
\left(\text { PPDw } w_{E N} \& \text { ISO 17772, }\right. \\
\text { overh })\end{array}$ & 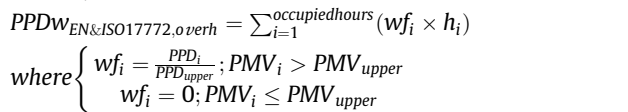 & $S$ & $\nu$ & A & 0 & & & \\
\hline \multirow[t]{6}{*}{ ISO 7730} & $\begin{array}{l}\text { Percentage of } \\
\text { Occupied hours } \\
\text { Outside the Range }(\% \\
\left.\text { POhOR }_{I S O} 7730, o p\right)\end{array}$ & 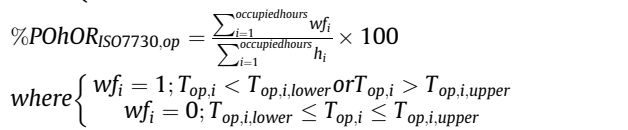 & $S$ & $r$ & $S$ & 0 & $r$ & & \\
\hline & $\begin{array}{l}\text { Percentage of } \\
\text { Occupied hours } \\
\text { Outside the Range }(\% \\
\left.\text { POhOR }_{\text {ISO } 7730, P M V}\right)\end{array}$ & 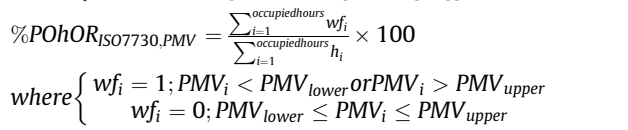 & $S$ & $r$ & $S$ & 0 & $r$ & & \\
\hline & $\begin{array}{l}\text { Degree hours* }\left(D h_{I S O}\right. \\
7730, \text { overh })\end{array}$ & 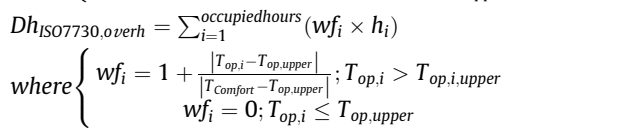 & $S$ & $\nu$ & A & 0 & & & \\
\hline & $\begin{array}{l}\text { Weighted PPD* } \\
\left(P P D w_{\text {ISO } 7730, \text { overh })}\right.\end{array}$ & $\begin{array}{l}P P D w_{\text {ISO7730,overh }}=\sum_{i=1}^{\text {occupiedhours }}\left(w f_{i} \times h_{i}\right) \\
\text { where }\left\{\begin{array}{c}w f_{i}=\frac{P P D_{i}}{P D_{\text {upper }}} ; P M V_{i} \geq P M V_{\text {upper }} \\
w f_{i}=0 ; P M V_{i}<P M V_{\text {upper }}\end{array}\right.\end{array}$ & $S$ & $r$ & A & $o$ & & & \\
\hline & $\begin{array}{l}\text { Averaged PPD } \\
(\text { AvgPPD) }\end{array}$ & $A v g P P D=\frac{\sum_{i=1}^{\text {occupiedthour }} P P D_{i}}{\sum_{i=1}^{\text {occupiedhours }} h_{i}}$ & & & $S$ & 0 & $r$ & & \\
\hline & $\begin{array}{l}\text { PPD over } \\
\text { time(PPDOT) }\end{array}$ & $P P D O T=\sum_{i=1}^{\text {occupiedhours }} P P D_{i}$ & & & $S$ & 0 & & & \\
\hline \multirow[t]{4}{*}{$\begin{array}{l}\text { ASHRAE } 55 \text { (2017) \& } \\
\quad \text { ASHRAE } 55 \text { (2020) }\end{array}$} & $\begin{array}{l}\text { Exceedance } \\
\text { Hours }\left(E H_{o p}\right)\end{array}$ & 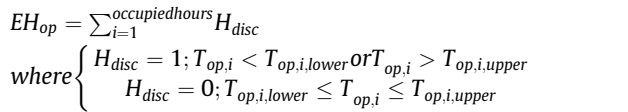 & A & $\nu$ & $S$ & 0 & & & \\
\hline & $\begin{array}{l}\text { Exceedance } \\
\text { Hours }\left(E H_{P M V}\right)\end{array}$ & $\begin{array}{l}E H_{P M V}=\sum_{i=1}^{\text {occupiedhours }} H_{\text {disc }} \\
\text { where }\left\{\begin{array}{l}H_{\text {disc }}=1 ;\left|P M V_{i}\right|>0.5 \\
H_{\text {disc }}=0 ;\left|P M V_{i}\right| \leq 0.5\end{array}\right.\end{array}$ & $S$ & & $S$ & $o$ & & & \\
\hline & $\begin{array}{l}\text { Weighted Exceedance } \\
\text { Hours }\left(W E H_{o p}\right)\end{array}$ & $\begin{array}{l}W E H_{o p}=\sum_{i=1}^{\text {occupiedhours }}\left(\left(T_{\text {op }, i}-T_{\text {op }, i \text { upper }}\right)\right. \\
\left.\times H_{\text {disc }, \text { warm }}+\left(T_{\text {op }, i \text { lower }-} T_{o p, i}\right) \times H_{\text {disc, cold }}\right)\end{array}$ & A & $\nu$ & $S$ & 0 & & & \\
\hline & $\begin{array}{l}\text { Weighted Exceedance } \\
\text { Hours }\left(W_{E H} H_{P M V}\right)\end{array}$ & 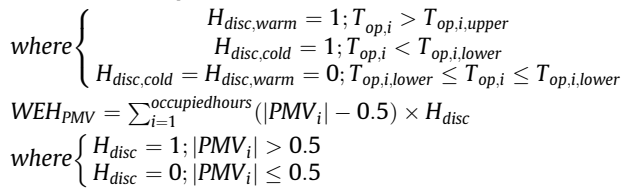 & S & & $S$ & 0 & & & \\
\hline
\end{tabular}




\begin{tabular}{|c|c|c|c|c|c|c|c|c|c|}
\hline \multirow[t]{2}{*}{ Standard } & \multirow[t]{2}{*}{ Index } & \multirow[t]{2}{*}{ Equation } & \multicolumn{7}{|l|}{ Measures } \\
\hline & & & $\begin{array}{l}\text { Static (S) / } \\
\text { Adaptive } \\
\text { (A) }\end{array}$ & $\begin{array}{l}\text { Category- } \\
\text { based }\end{array}$ & $\begin{array}{l}\text { Symmetric (S) / } \\
\text { Asymmetric (A) }\end{array}$ & $\begin{array}{l}\text { All hours (A) / } \\
\text { occupied } \\
\text { hours }(0)\end{array}$ & $\begin{array}{l}\text { Normalized } \\
\text { to occupied } \\
\text { hours } \\
\end{array}$ & $\begin{array}{l}\text { Short- } \\
\text { term } \\
\text { criterion }\end{array}$ & $\begin{array}{l}\text { Long- } \\
\text { term } \\
\text { criterion }\end{array}$ \\
\hline $\begin{array}{l}\text { CIBSE Guide A (2006) \& } \\
\text { CIBSE Guide A } \\
\text { (2015) }\end{array}$ & $\begin{array}{l}\text { Percentage of } \\
\text { Occupied hours } \\
\text { Outside the Range } \\
\left(\text { POhOR }_{\text {CIBSEGuideA,op }}\right)\end{array}$ & 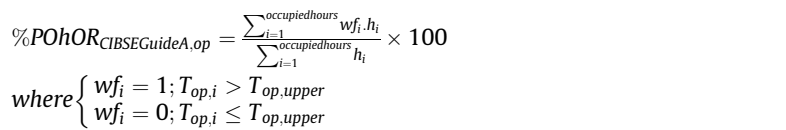 & $S$ & & A & 0 & $r$ & & $r$ \\
\hline CIBSE Guide A (2015) & $\begin{array}{l}\text { Percentage of } \\
\text { Occupied hours } \\
\text { Outside the Range } \\
\left(\text { POhOR } \text { CIBSEGuideA.PMV }_{\text {. }}\right.\end{array}$ & $\begin{array}{l}\% \text { POhOR } R_{C I B S E G u i d e A, P M V}=\frac{\sum_{i=1}^{\text {occiededhour }} w f_{i} h_{i}}{\sum_{i=1}^{\text {occupiedhours }} h_{i}} \times 100 \\
\text { where }\left\{\begin{array}{l}w f_{i}=1 ; P M V_{i}>0.5 \\
w f_{i}=0 ; P M V_{i} \leq 0.5\end{array}\right.\end{array}$ & $S$ & & A & o & $\boldsymbol{r}$ & & $r$ \\
\hline \multirow[t]{3}{*}{ CIBSE TM52 ${ }^{(1)}$} & $\begin{array}{l}\text { Hours of Exceedance } \\
(\mathrm{He}) \text { "Criterion (1)" }\end{array}$ & 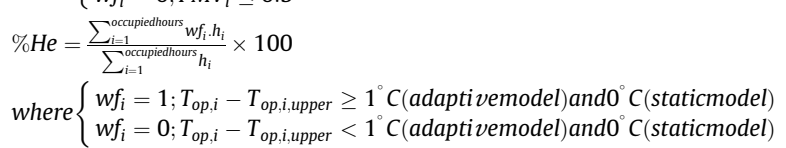 & $A$ & & $A$ & o & $r$ & & $r$ \\
\hline & $\begin{array}{l}\text { Daily Weighted } \\
\text { Exceedance }\left(W_{e}\right) \\
\text { "Criterion }(2) "\end{array}$ & $\begin{array}{l}W_{e}=\sum_{i=1}^{\text {occupiedhours,daily }}\left(w f_{i} \times h_{i}\right) \\
\text { where }\left\{\begin{array}{c}w f_{i}=T_{o p, i}-T_{o p, i, u p p e r} ; T_{o p, i}>T_{o p, i, u p p e r} \\
w f_{i}=0 ; T_{o p, i} \leq T_{o p, i, u p p e r}\end{array}\right.\end{array}$ & $A$ & & $A$ & o & & $r$ & \\
\hline & $\begin{array}{l}\text { Upper Limit } \\
\text { Temperature }\left(T_{\text {upp }}\right) \\
\text { "Criterion }(3) \text { (2) }\end{array}$ & $T_{o p, i}-T_{o p, i, i p p e r} \ngtr 4^{\circ} \mathrm{C}$ & $A$ & & $A$ & o & & & \\
\hline CIBSE TM59 & $\begin{array}{l}\text { Percentage of } \\
\text { Sleeping hours } \\
\text { Outside the Range }(\% \\
\left.\text { PShOR }_{\text {CIBSE TM59 }}\right)\end{array}$ & $\begin{array}{l}\% \text { PShOR } \\
\text { CIBSETM59 }=\frac{\sum_{d=1}^{d=355} \sum_{10 p m}^{7 a m} m f_{i}, h_{i}}{\sum_{d=1}^{d=365} \sum_{10 p m}^{a m m} h_{i}} \times 100 \\
\text { where }\left\{\begin{array}{l}w f_{i}=1 ; T_{o p, i}>26^{\circ} \mathrm{C} \\
w f_{i}=0 ; T_{o p, i} \leq 26^{\circ} \mathrm{C}\end{array}\right.\end{array}$ & $S$ & & $A$ & 0 & $\boldsymbol{r}$ & & $r$ \\
\hline Passive House & $\begin{array}{l}\text { Percentage of hours } \\
\text { Outside the Range (\% } \\
\text { PhOR) }\end{array}$ & $\begin{array}{l}\% \text { PhOR }=\frac{\sum_{i=1}^{\text {anmualhours }} w f_{f_{i}} h_{i}}{\sum_{i=1}^{\text {annulhouls }} h_{i}} \times 100 \\
\text { where }\left\{\begin{array}{l}w f_{i}=1 ; T_{a, i}>25^{\circ} \mathrm{C} \\
w f_{i}=0 ; T_{a, i} \leq 25^{\circ} \mathrm{C}\end{array}\right.\end{array}$ & $S$ & & $A$ & $A$ & & & $r$ \\
\hline
\end{tabular}


index that should be calculated for overheating period and overcooling period separately. The limit of this index is that, (i) it is category-based, (ii) it lacks the normalization to the number of occupied hours, this makes the comparison of buildings with different occupancy profiles troublesome, (iii) it is only based on the operative temperature and neglects the effects of personal factors (metabolic rate and clothing factor) and environmental parameters (relative humidity and air velocity) in the determination of thermal comfort, and (iv) no maximum thresholds are prescribed to limit the short-term and long-term overheating.

The $P P D w$ index is proposed only for the $P M V / P P D$ model (see Section 3.1). It assumes the time (occupied hours) in which the $P M V$ exceeds the comfort boundaries is weighted with a weighting factor $\left(w_{i}\right)$. The wfi is a module that quantifies the measured or simulated PPD over the corresponding PPD limit. Similar to the $D h$ index, the assessment of overheating and overcooling discomfort is separated, making it asymmetric. The PPDw allows the consideration of the hourly percentage of dissatisfaction accumulation over time. However, the limitation of this index is that (i) it is only based on PMV/PPD model, (ii) it is not normalized to the number of occupied hours, (iii) no maximum thresholds are prescribed, and (iv) it is category-based. The time-integrated overheating/discomfort indices in EN 15251 and EN 16798 standards are listed in Table 5.

3.2.1.2. ISO 7730 and ISO 17772 . For time-integrated thermal discomfort assessment, ISO 7730 provides five methods, namely Percentage of Occupied hours Outside the Range (\%POhOR ISO 7730), Degree hours ( $\left.D h_{I S O} 7730\right), P P D$ weighted (PPDw $\left.w_{I S O} 7730\right)$, average $P P D$ (avgPPD), and PPD Over Time (PPDOT) criteria.

The \%POhOR ISO 7730 is similar to \%POhOR $R_{E N}$. The $D h_{I S O} 7730$ index however has some differences compared to the $D h_{E N}$ index related to the calculation of weighting factor $\left(\mathrm{wf}_{\mathrm{i}}\right)$. Based on the ISO 7730 formulation of $\mathrm{wf}_{\mathrm{i}}$, it penalizes the recurrence of exceedance and weights the discomfort by the amplitude of the comfort range (i.e., it results in higher discomfort for the same exceedance where the stricter thermal conditions are assigned such as in Category I) [29]. The only difference in the calculation of the PPD $w_{I S O} 7730$ compared to the $P P D w_{E N}$ is that the ISO 7730 method increases the value of the $P P D w_{I S O} 7730$ even if the $P M V$ is equal to the upper or lower limit of the comfort range.

The average $P P D$ (avgPPD) index shows the average $P P D$ calculated over the occupied hours. The avgPPD does not rely on the limits of any specific comfort category; it quantifies the accumulation of discomfort over time without the problem of discontinuity at the boundaries of the comfort categories. It is a useful index to compare and optimize the thermal comfort performance of different buildings independent of the occupancy expectation levels. However, (i) this index is only applicable to the PMV/PPD model and (ii) it is symmetric.

The PPD Over Time (PPDOT) consists of the summation of all PPDs during the occupied hours. The PPDOT does not depend on the limits of comfort categories. This index has some disadvantages such as, (i) it is only based on the PMV/PPD model, (ii) it is symmetric, and (iii) it is not normalized to the occupied hours. ISO 7730 includes threshold limits on none of the above indices to limit the short-term and long-term overheating/discomfort.

All the recommendations on time-integrated overheating/discomfort indices and criteria in ISO 17772 are identical to that of EN 16,798 (see Section 3.2.1.1). Table 5 summarizes all the timeintegrated overheating/discomfort indices in ISO 7730 and ISO 17772 .

3.2.1.3. ASHRAE 55 (2017) and ASHRAE (2020). For time-integrated thermal discomfort assessment, both versions of ASHRAE 55 provide two principal and identical indices in informative Appendix
L, namely, Exceedance Hours $(E H)$ and Weighted Exceedance Hours $(W E H)$. Moreover, some metrics such as expected number of episodes, rate of change exceedance, and local discomfort exceedances within a time period of interest exist in ASHRAE 55; however, the calculation methods are not presented.

The $E H$ index shows the number of occupied exceedance hours when the $P M V$ or the operative temperature is outside the static and adaptive comfort zone boundaries (see Section 3.1). The $E H$ can be calculated using a binary weighting factor $\left(\mathrm{H}_{\text {disc }}\right)$. The $\mathrm{H}_{\text {disc }}$ is one during the out-of-range conditions and is zero during the time within the comfort zone. The $E H$ index quantifies the general discomfort without distinguishing between overheating and overcooling discomfort. This index can be criticized since, (i) it does not include the intensity of discomfort, (ii) no limits are prescribed as the acceptable deviation of the $E H$ index, (iii) it is symmetric, (iv) it is category-based if adaptive comfort model is applied, and (v) it is not normalized to the occupied hours.

The WEH quantifies the severity of discomfort during the occupied hours which is analogous to the Degree hours index described in Section 3.2.1.1. To calculate the WEH, ASHRAE 55 provides a formula based on the PMV for the static comfort model and a formula based on operative temperature for the adaptive comfort model. The $W E H$ based on the PMV is the summation of the $|P M V|-0.5$ weighted by the binary weighting factor $\left(\mathrm{H}_{\text {disc }}\right)$ during the occupied hours. And, the WEH based on the operative temperature consists of the summation of two factors during the occupied hours, (i) the difference between the operative temperature and minimum adaptive comfort threshold (if $T_{o p, i}<T_{o p, i, l o w e r}$ ) weighted by the $H_{\text {disc }}$ and (ii) the difference between the operative temperature and maximum adaptive comfort threshold (if $T_{o p, i}>T_{o p, i, u p p e r}$ ) weighted by the $\mathrm{H}_{\text {disc }}$. The WEH has some limitations since, (i) it is not normalized to the occupied hours, (ii) no limits are prescribed as the acceptable deviation of the WEH index, (iii) it is symmetric, and (iv) it is category-based if the adaptive comfort model is applied. All the time-integrated discomfort indices in ASHRAE 55 are summarized in Table 5.

\subsubsection{CIBSE Guide A (2006), CIBSE TM52, CIBSE Guide A (2015), and CIBSE TM59.}

CIBSE Guide A (2006). CIBSE Guide A (2006) defines Percentage of Occupied hours Outside the Range (\%OHOR ${ }_{\text {CIBSE Guide A,op }}$ ) as a single index to assess the time-integrated overheating, only for naturally ventilated buildings. The \%POhOR ${ }_{C I B S E}$ Guide A,op index consists of the summation of all occupied hours exceeding the fixed maximum operative temperature limit (i.e., benchmark peak temperature) (see Section 3.1) over the total number of occupied hours. The \% $P_{\text {POhOR }}$ CIBSE Guide A,op is an asymmetric index focusing on overheating discomfort. According to CIBSE Guide A (2006) overheating criteria,

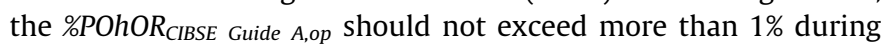
the occupied hours year-round in the bedrooms and living room in dwellings. It can be criticized since, (i) it is based on operative temperature and does not take into account the influential personal factors (i.e., clothing factor and metabolic rate) and environmental parameters (i.e., relative humidity and air velocity) in the determination of thermal comfort, (ii) only a long-term annual overheating criterion is prescribed, and (iii) it does not consider the intensity of overheating.

CIBSE TM52. CIBSE TM52 introduces a method consisting of three criteria for time-integrated overheating evaluation, only for freerunning buildings. The criterion (1) and criterion (2) are concerned with time-integrated overheating; however, the criterion (3) is a "right now" and "right here" approach to limit the instant overheating in buildings. The three criteria, taken together, provide a holistic approach to overheating risk assessment and a zone or building that fails any two of the three criteria is classed as overheated. 


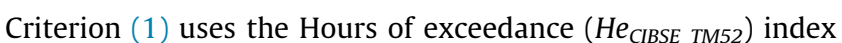
that is the percentage of hours when the indoor operative temperature is exceeding the maximum temperature limit (see Section 3.1) by one or greater than one degree $\mathrm{K}$ over the total number of occupied hours. The $H_{\text {CIBSE TM52 }}$ should be calculated during a typical non-heating season (1 May to 30 September). According to its definition, the He CIBSE TM52 is an asymmetric index focusing on overheating discomfort during the summertime. For He CIBSE TM52 index, CIBSE TM52 allows for a maximum deviation of $3 \%$ during the occupied hours. The criterion (1) can be criticized since, (i) it neglects the intensity of overheating, (ii) it is specific for the period from May to September, it excludes the potential overheating events that can happen in other periods [60], (iii) it is based on operative temperature and does not take into account the influential personal factors (i.e., clothing factor and metabolic rate) and environmental parameters (i.e., relative humidity and air velocity) in the determination of thermal comfort, and (iv) it sets a criterion only to limit long-term overheating.

In criterion (2), CIBSE TM52 defines the daily Weighted exceedance $\left(W_{e}\right)$ index to deal with the severity of overheating within any one day. The $W_{e}$ index resembles the Degree hours metric quantifying the number of exceedance hours weighted by a factor $(\mathrm{WF})$. The $\mathrm{WF}$ is the module of the difference between the operative temperature and maximum temperature limit (see Section 3.1) ( imilar to the $\mathrm{wf}_{\mathrm{i}}$ in the calculation of $D h$ ). The $W_{e}$ is an asymmetric index concerned with overheating discomfort. CIBSE TM52 allows the $W_{e}$ index to reach equal to or $<6$ in any one day setting a short-term (daily) criterion to limit the overheating during the heatwave events. The criterion (2) has some limitations such as, (i) it is not normalized to the occupied hours, (ii) it is only based on the operative temperature and does not take into account the influential personal factors (i.e., clothing factor and metabolic rate) and environmental parameters (i.e., relative humidity and air velocity) in the determination of thermal comfort, and (iii) it sets a criterion only to limit short-term overheating.

The criterion (3) is simply setting an absolute maximum value, in which the indoor operative temperature shall not exceed by $4 \mathrm{~K}$. It sets a limit beyond the adaptation actions will be insufficient to restore the personal comfort aiming at covering the extreme heatwave events in the future climates. This asymmetric criterion does not account for the accumulation of overheating over time. It can be criticized because it only assigns a threshold value for operative temperature but not for other environmental parameters such as relative humidity and air velocity.

CIBSE Guide A (2015). For time-integrated overheating evaluation in mechanically cooled and naturally ventilated buildings, CIBSE Guide A (2015) uses the Percentage of Occupied hours Outside

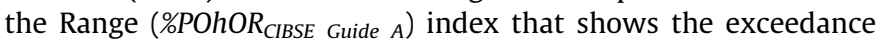
hours over the upper comfort threshold represented in PMV or operative temperature scale (see Section 3.1). It is thus an asymmetric index. To limit the long-term overheating, the calculated \% POhOR $_{\text {CIBSE Guide A }}$ should not exceed the maximum limit of comfort for more than $3 \%$ during the occupied hours. We can criticize this index since, (i) it only considers the frequency of overheating, and (ii) only a long-term (annual) threshold value is prescribed.

For time-integrated overheating evaluation in free-running buildings, CIBSE Guide A (2015) follows the three criteria that are previously described in CIBSE TM52.

CIBSE TM59. The criteria for homes predominantly mechanically conditioned follows the CIBSE fixed temperature test which states that all zones should not exceed an operative temperature of $26{ }^{\circ} \mathrm{C}$ for more than $3 \%$ of the annual occupied hours.

For homes predominantly naturally ventilated, CIBSE TM59 requires compliance based on passing the two following criteria, (i) in living rooms, kitchens, and bedrooms, the criterion (1) of CIBSE TM52 should be respected, and (ii) in the bedrooms during the sleeping hours from $10 \mathrm{pm}$ to $7 \mathrm{am}$, the operative temperature should not exceed $26^{\circ} \mathrm{C}$ for more than $1 \%$ of total annual hours. The latter leads to the definition of an asymmetric index called Percentage of Sleeping hours Outside the Range (\%PShOR CIBSE TM59). $_{\text {. }}$

Overall, following the two above criteria of CIBSE TM59 has some limitations, (i) both criteria are based on operative temperature and do not take into account the influential personal factors (i.e., clothing factor and metabolic rate) and environmental parameters (i.e., relative humidity and air velocity) in the determination of thermal comfort, and, (ii) both criteria neglects the intensity of overheating, (iii) both criteria set threshold values to limit longterm overheating (i.e., seasonal and annual), (iv) the \%PShOR TM59 index makes a rough estimation regarding the sleeping time and duration, and (v) the threshold selection for \%PShOR ${ }_{C I B S E}$ TM59 is contentious, for instance, World Health Organization (WHO) suggests a threshold of $24{ }^{\circ} \mathrm{C}$ for bedrooms.

All the time-integrated overheating indices in CIBSE norms are summarized in Table 5.

3.2.1.5. Passive house. Regarding the time-integrated overheating evaluation in buildings without active cooling or with passive cooling, the Passive House standard contains an asymmetric index called the Percentage of hours outside the range (\%PhOR) (see Table 5). The \%PhOR index shows the percentage of hours (occupied and unoccupied) exceeding the pre-defined threshold value of $25{ }^{\circ} \mathrm{C}$. For a building to comply with the requirements of Passive House standard, the \%PhOR should not exceed $10 \%$ throughout the year for all living areas. This approach can be criticized since, (i) it only sets a long-term (annual) overheating criterion, (ii) it is only based on the operative temperature and does not take into account the influential personal factors (i.e., clothing factor and metabolic rate) and environmental parameters (i.e., relative humidity and air velocity) in the determination of thermal comfort, (iii) it includes the discomfort hours during the unoccupied periods, and (iv) it neglects the intensity of overheating.

\subsubsection{National building codes based on the Energy Performance of building Directive (EPBD)}

In 2012, the European Commission established a legislative framework that includes the Energy Performance of Building Directive (EPBD) [61]. The EPBD aims at promoting energy efficiency and decarbonized building stock by $2050 \mathrm{~s}$ as well as creating a stable environment in buildings. General regulations made by EPBD must be interpreted and implemented by the Member States in the national building regulations. In this section, we investigate the overheating evaluation methods in the national building codes of Belgium, Germany, France, the UK, and the Netherlands.

Belgium. In Belgium, each region (i.e., Brussels, Flanders, and Wallonia) is in charge of implementing the EPBD individually. The region of Brussels "Région de Bruxelles-Capitale" decided to adopt the criteria defined by Passive House standard for the residential buildings that are new or assimilated to new $[62,63]$. The overheating compliance in Brussels is achieved by not exceeding $25^{\circ} \mathrm{C}$ by $5 \%$ during the occupied hours throughout the year. On the other hand, the regions of Wallonia "Région wallonne" and Flanders "Vlaams Gewest" establish a quasi-steady-state heat balance method derived from ISO 13790 for new and renovated residential buildings without active cooling [64]. Accordingly, a timeintegrated overheating index $\mathrm{I}_{\text {overh }}[\mathrm{Kh}]$ is introduced which sums up the normalized monthly excess of heat gains $\mathrm{Q}_{\text {excess norm, } \mathrm{m}}[\mathrm{Kh}]$ in relation to the indoor set-point temperature, 
$I_{\text {overh }}=\sum_{m=1}^{12} Q_{\text {excessnorm }, \mathrm{m}}[K h]$

$Q_{\text {excessnorm }, m}=\frac{\left(1-\eta_{\text {util,overh }, m}\right) \cdot Q_{g, \text { overh }, m}}{H_{T, \text { overh }}+H_{V, \text { overh }, m}} \cdot \frac{1000}{3,6}$

Where $\eta_{\text {util,overh,m }}[-]$ is the utilization factor depending on the ratio between the monthly heat loss and heat gain, $Q_{g, o v e r h, m}$ is the monthly solar and internal heat gains [MJ], $H_{T \text {,overh }}$ is the conduction heat transfer coefficient $[\mathrm{W} / \mathrm{K}]$, and $\mathrm{H}_{\mathrm{V}, \text { overh, } \mathrm{m}}$ is the monthly ventilation heat transfer coefficient $[\mathrm{W} / \mathrm{K}]$. An acceptable range of $\left(1000 \mathrm{Kh}<\mathrm{I}_{\text {overh }}<6500 \mathrm{Kh}\right)$ over the annual period is recommended.

This method has some disadvantages such as, (i) it is calculated by heat balance equations, it does not take into account the influential personal factors (i.e., clothing factor and metabolic rate) and environmental parameters (i.e., air temperature, radiant temperature, relative humidity, and air velocity) in the determination of thermal comfort, (ii) it neglects the adaptation actions taken by the occupants, (iii) it is based on monthly averages of heat loads and thus not able to track short-term heatwave events, (iv) it is not normalized to the occupied hours, (v) it takes into account the unoccupied hours, and (vi) only a long-term (annual) threshold value is suggested.

Germany. In Germany, the national building code based on the EPBD was translated into DIN 4108 [65] to define the overheating calculation method and criteria for buildings with and without passive cooling. The method in DIN 4108 consists of two criteria for overheating protection, and compliance is achieved through passing one of them.

Criterion (1) is a simplified method with standardized boundary conditions. Accordingly, the summer overheating protection must be ensured in the most critical room in terms of solar and endogenous heat gains. For this aim, the solar transmittance $S_{\text {vorh }}[-]$ index is proposed which is the function of room size, window size, window type, and solar shading devices,

$S_{v o r h}=\frac{\sum_{j}\left(A_{W, j} \times g_{\text {tot }, j}\right)}{A_{G}}$

Where $A_{W, j}$ is window area of zone $j\left[\mathrm{~m}^{2}\right], g_{\text {tot }, j}$ is total energy transmittance of the glazing including sun protection of zone $\mathrm{j}$ [-], and $A_{G}$ is the net floor area $\left[\mathrm{m}^{2}\right]$. The calculated $\mathrm{S}_{\text {vorh }}[-]$ should not exceed the maximum value of solar transmittance $S_{\text {zul }}[-]$ calculated by,

$S_{z u l}=S_{1}+S_{2}+S_{3}+S_{4}+S_{5}+S_{6}$

$S_{\text {vorh }} \leq S_{\text {zul }}$

The $S_{1}$ to $S_{6}$ are proportional solar input parameters given in DIN 4108 as following,

$S_{1}$ for night ventilation type, climatic region, and usage

$\mathrm{S}_{2}$ for the base area correction factor

$S_{3}$ for solar protection of glass

$\mathrm{S}_{4}$ for window pitch

$S_{5}$ for window orientation

$S_{6}$ for passive cooling

Criterion (1) directly concerns with the solar gains through the glazing areas. It has some limitations such as, (i) it excludes the internal gains induced by the equipment and occupants, (ii) It does not accumulate the overheating discomfort over time (i.e., timeindependent), (iii) it neglects the influential personal factors (i.e., clothing factor and metabolic rate) and environmental parameters (i.e., air temperature, radiant temperature, relative humidity, and air velocity) in the determination of thermal comfort, and (iv) the notion of occupant adaptation is undermined. It was shown by
Krone et al. [66] that only compliance to the first criterion does not guarantee a comfortable thermal environment in buildings.

In Criterion (2), the symmetric Degree hours ( $D h$ ) index should be calculated for the most critical room of the building via the simulation. The reference temperature for the $D h$ calculation depends on climatic region (i.e, $25{ }^{\circ} \mathrm{C}$ for "Klimaregion A" Rostock, $26{ }^{\circ} \mathrm{C}$ for "Klimaregion B" Potsdam, and $27^{\circ} \mathrm{C}$ for "Klimaregion C" Mannheim). The compliance is required on the value of $D h$ which should not exceed the specified value of $1200 \mathrm{Kh}$ during the year. Criterion (2) overcomes the first two limitations of the criterion (1), however, (i) it still neglects the influential personal factors (i.e., clothing factor and metabolic rate) and environmental parameters (i.e., relative humidity and air velocity) in the determination of thermal comfort, (ii) it is not providing any criteria to limit the short-term overheating events, and (iii) it does not allow for occupant adaptation, and (iv) it is not normalized to the occupied hours.

France. In France, the EPBD is translated into a standard called "Règlementation Environnementale" (RE2020) [67]. The RE2020 uses the Degree hours $(D h)$ index to evaluate the discomfort during the summer in new residential buildings. The reference temperature for the $D h$ calculation should be derived from the maximum temperature limits of the Category II of the adaptive comfort model in EN 15251 (see Section 3.2.1.1). According to RE2020, the symmetric $D h$ should be evaluated for a weather scenario similar to that of 2003 heatwaves. The RE2020 sets a maximum threshold of 1250 Kh corresponding to a period of 25 days when the indoor operative temperature is continuously at $30{ }^{\circ} \mathrm{C}$ during the day and $28{ }^{\circ} \mathrm{C}$ at night. The criterion is applied to all climate zones across the country. Also, RE2020 sets the lowest threshold at $350 \mathrm{Kh}$ beyond the penalties that will be applied in the calculation of energy performance.

The time-integrated overheating evaluation method in RE2020 has some limitations: (i) it imposes criterion only to limit the long-term overheating, (ii) it is based on operative temperature neglecting the personal factors (i.e., clothing factor and metabolic rate) and environmental parameters (i.e., air temperature, relative humidity, and air velocity) in the determination of thermal comfort, (iii) even though France consists of the regions with very different climatic characterization (the Oceanic to the Mediterranean), the same comfort zone boundaries are suggested, and (iv) it is not normalized to the occupied hours.

$U k$. In the UK, the overheating evaluation method according to the EPBD is included within the Approved Document L1A for new dwellings [68] (there is no method for overheating evaluation in existing dwellings in Approved Document L1B [69]). The Approved Document L1A is updated regularly by the DCLG. It worth mentioning that the DCLG review report in 2014 did not present any proposed actions to the overheating calculation method [70]. Hence, the latest edition of the Approved Document L1A in 2013 with amendments in 2016 follows the same method and criteria of its previous edition published in 2013 [71] which enforces the SAP [72] to set the overheating criteria. We should also mention that according to [73], a recent draft of a consultation document on changes to Approved Document L by the UK government, there is an ongoing effort to replace the SAP methodology with more recent methodologies proposed for residential buildings such as the one in CIBSE TM59.

The SAP provides the overheating assessment method in Appendix P requiring the compliance to "overheating check". The SAP procedure introduces an internal threshold index ( $\left.\mathrm{T}_{\text {threshold }}\right)$ for overheating evaluation during the summer. The $T_{\text {threshold }}\left[{ }^{\circ} \mathrm{C}\right]$ is used to estimate the likelihood of high internal temperatures. The $T_{\text {threshold }}$ is calculated by summing up the mean external temperature during the summer month $T_{e}^{\text {summer }}$, the ratio of monthly 
heat gains and heat losses, and an increment related to the building thermal mass $\Delta T_{\text {mass. }}$. The formula to calculate the $T_{e}^{\text {summer }}$ is,

$T_{\text {threshold }}=T_{e}^{\text {summer }}+\mathrm{G} / \mathrm{H}+T_{\text {mass }}$

Where $G$ is the sum of monthly solar and internal gains [W] and $H$ is the monthly ventilation and fabric heat loss [W]. The $\Delta T_{\text {mass }}$ can be calculated by,

$\Delta T_{\text {mass }}=2.0-0.007 \times$ TMPifTMP $<285$

Where TMP is the thermal mass parameter for building envelope components $\left[\mathrm{kJ} / \mathrm{m}^{2} \mathrm{~K}\right]$. According to the SAP, the $T_{\text {threshold }}$ should be calculated for June, July and August. The level of likelihood of high internal temperatures during hot weather conditions is listed in Table 6. The disadvantages of the SAP method are, (i) it is specific for summertime overheating evaluation, (ii) It does not consider the influential personal factors (i.e., metabolic rate and clothing) and environmental parameters (i.e., radiant temperature, relative humidity, and air velocity) in the determination of thermal comfort, (iii) it neglects the occupant adaptation, (iv) it takes into account the unoccupied hours, (v) it is not normalized to the occupied hours, and (v) only the long-term (i.e., monthly) overheating is characterized. It was shown by McLeod and Swainson [27] that in complex building typologies that are inherently vulnerable to overheating such as a single-sided dwelling with high internal gains in the urban context, the steady-state procedure of SAP is not reliable in validating the design performance.

Netherlands. In the Netherlands, the EPBD was interpreted and included within NTA 8800 [74]. NTA 8800 contains the methods and criteria for overheating assessment in Almost Energy Neutral

Table 6

The threshold temperature ranges corresponding to the likelihood of high internal temperatures.

\begin{tabular}{ll}
\hline$\left.T_{\text {threshold }}{ }^{\circ} \mathrm{C}\right]$ & $\begin{array}{l}\text { Likelihood of high internal temperatures } \\
\text { during hot weather }\end{array}$ \\
\hline$>23.5^{\circ} \mathrm{C}$ & Not significant \\
$22^{\circ} \mathrm{C}-23.5^{\circ} \mathrm{C}$ & Slight \\
$22^{\circ} \mathrm{C}-23.5^{\circ} \mathrm{C}$ & Medium \\
$\geq 23.5^{\circ} \mathrm{C}$ & High \\
\hline
\end{tabular}

Table 7

The $\mathrm{Wf}_{\mathrm{i}, \text { NTA } 8800}$ corresponding to the PMV and PPD values for the calculation of GTO.

\begin{tabular}{lll}
\hline PMV $[-]$ & PPD $[\%]$ & $\mathrm{Wf}_{\mathrm{i}, \mathrm{NTA} 8800[-]}$ \\
\hline 0 & 5 & 0 \\
0,5 & 10 & 1,0 \\
0,7 & 15 & 1,5 \\
1,0 & 26 & 2,6 \\
\hline
\end{tabular}

Buildings (BENG) (in Dutch "Bijna Energie Neutrale Gebouwen"). The overheating evaluation requires the determination of dimensionless index $\mathrm{TO}_{\text {juli }}$. The value is calculated depending on the façade surface per orientation. For instance, a terraced house has two outcomes, and a corner house has three outcomes. The $\mathrm{TO}_{\text {juli }}$ should be calculated for the month of July using the formula below,

$T O_{j u l i, o r, z i}=\frac{\left(Q_{C, n d, j u l i, o r, z i}-Q_{C, H P, j u l i, o r, z i}\right) \times 1000}{\left(H_{C, D, j u l i, o r, z i}+H_{g r, a n, j u l i, o r, z i}+H_{C, v e . j u l i, o r, z i}\right) \times h_{j u l i}}$

Where $Q_{c, n d, j u l i, o r, z i}$ is cooling demand for orientation or in zone zi [kWh], $\mathrm{Q}_{\mathrm{C}, \mathrm{HP}, \mathrm{juli}, \mathrm{or}, \mathrm{zi}}$ is the extracted energy from the cooling unit by the booster heat pump for orientation or in zone zi [kWh], $\mathrm{H}_{C, \text { D.juli,or,zi }}$ is direct heat transfer coefficient by transmission between the heated space and the outdoor air except for the ground floor for orientation or in zone zi $[\mathrm{W} / \mathrm{K}], \mathrm{H}_{\mathrm{gr}, \text { an.juli,or,zi }}$ is the direct heat transfer coefficient by the transmission for building elements in thermal contact with the ground for orientation or in zone zi $[\mathrm{W} / \mathrm{K}], \mathrm{H}_{\mathrm{C}, \mathrm{ve}, \mathrm{jul} \text { i,or,zi }}$ is the direct heat transfer coefficient through ventilation for orientation or in zone $z i[W / K]$, and $h_{j u l i}$ is the total time over the month of July. The $\mathrm{TO}_{\text {juli }}$ is an indication number derived from the average cooling requirement of the entire building. A maximum limit value of 1 is specified for the $\mathrm{TO}_{\text {juli }}$. It should be mentioned that If the building is provided with cooling, there is then no need for the calculation of the $\mathrm{TO}_{\text {juli }}$.

NTA 8800 also provides a method based on the weighted limit temperature (GTO) to calculate the risk of overheating more accurately when the $\mathrm{TO}_{\text {juli }}$ slightly exceeds its limit value. In the GTO method, the hours of when the actual or calculated PMV exceeds the limit value of +0.5 are weighted proportional to the PPD as shown in Table 7. The formula to calculate the GTO is,

$G T O=\sum W f_{i, N T A 8800}$

The GTO is calculated for the living areas with a threshold value of 450 . The method provided by NTA 8800 for overheating evaluation has some limitations such as, (i) by only using the $\mathrm{TO}_{\text {juli }}$ index it is not possible to track and limit the short-term (i.e., hourly, daily, and weekly) overheating events, (ii) $\mathrm{TO}_{\text {juli }}$ takes into account the unoccupied hours, (iii) the $\mathrm{TO}_{\text {juli }}$ is calculated by heat balance equations, it does not take into account the influential personal factors (i.e., clothing factor and metabolic rate) and environmental parameters (i.e., air temperature, radiant temperature, relative humidity, and air velocity) in the determination of thermal comfort, (iv) the GTO index is not normalized to the occupied hours, (v) both methods are specific for the long-term overheating during the month of July and neglect overheating occurrence in other months even during the summer, and (vi) both mehtods exclude the occupant adaptation notion.

In Table 8, we summarize the overheating assessment methods in EPBD regulatory documents in five abovementioned countries with some key information. The occupant adaptation to the ther-

Table 8

Summary of overheating assessment methods in national building codes based on the EPBD.

\begin{tabular}{|c|c|c|c|c|c|c|}
\hline Country & Regulatory documents based on EPBD & $\begin{array}{l}\text { Static } \\
\text { model }\end{array}$ & $\begin{array}{l}\text { Adaptive } \\
\text { model }\end{array}$ & $\begin{array}{l}\text { Based on heat } \\
\text { balance }\end{array}$ & $\begin{array}{l}\text { Based on comfort } \\
\text { parameters }\end{array}$ & $\begin{array}{l}\text { Multizonal or } \\
\text { single-zone } \\
\text { approach }\end{array}$ \\
\hline Belgium (Brussels) & $\begin{array}{l}\text { Réglementation sur la Performance Energétique des } \\
\text { Bâtiments (PEB Brussels) }\end{array}$ & $\boldsymbol{r}$ & & & $\boldsymbol{\nu}$ & Multi-zonal \\
\hline $\begin{array}{l}\text { Belgium (Wallonia } \\
\text { and Flanders) }\end{array}$ & $\begin{array}{l}\text { Réglementation sur la Performance Energétique des } \\
\text { Bâtiments (PEB Wallonia)Energieprestatie en } \\
\text { Binnenklimaat (EPB Flanders) }\end{array}$ & $\boldsymbol{r}$ & & $\boldsymbol{}$ & & Single zone \\
\hline Germany & Deutsches Institut für Normung (DIN) 4108-6 & レ & & レ(Criterion 1) & $\boldsymbol{\nu}($ Criterion 2$)$ & Multi-zonal \\
\hline France & Règlementation Environnementale(RE2020) & & $\boldsymbol{r}$ & & レ & Multi-zonal \\
\hline UK & Approved Document L1A & レ & & $\boldsymbol{}$ & & Single zone \\
\hline Netherlands & Netherlands Technical Agreement (NTA) 8800 & $\boldsymbol{r}$ & & $\boldsymbol{レ ( C r i t e r i o n ~} 1)$ & $\boldsymbol{\nu}($ Criterion 2$)$ & Multi-zonal \\
\hline
\end{tabular}


mal environment is largely neglected in the reviewed building codes except for France. The building codes in Belgium (Wallonia and Flanders), Germany, the UK, and the Netherlands have only or at least one criterion based on the steady-state heat balance equations. The heat balance approach does not fully represent the occupant thermal sensation which is determined by six major parameters (i.e., air temperature, radiant temperature, relative humidity, air velocity, metabolic rate, and clothing,). The evidence of compliance in Belgium (Wallonia and Flanders) and the UK is provided by considering the heat balance of the whole building as a single zone. This approach prevents the identification of the most critical zones within a building and includes the effect of trivial zones (e.g., attic, warehouse etc.) in overheating assessments.

\subsubsection{Scientific literature}

3.2.3.1. Indoor overheating Degree (IOD), Ambient Warmness Degree $(A W D)$, and overheating escalation factor ( $\left.\boldsymbol{\alpha}_{\mathbf{I O D} / \mathbf{A W D}}\right)$. Hamdy et al. [14] proposed a climate change-sensitive overheating evaluation method based on three indices called Indoor Overheating Degree $(I O D)$, Ambient Warmness Degree (AWD), and Overheating Escalation Factor ). The Indoor Overheating Degree (IOD) index is the summation of the temperature difference between the indoor operative temperature and a preferred comfort temperature averaged over the total number of zonal occupied hours. In other words, it incorporates the frequency by integrating the intensity over the occupied hours in different building zones. The $I O D\left[{ }^{\circ} \mathrm{C}\right]$ can be calculated by,

$I O D=\frac{\sum_{z=1}^{Z} \sum_{i=1}^{N_{\text {occ }}(z)}\left[\left(T_{\text {op }, i, z}-T_{\text {op }, i, z, u p p e r}\right)^{+} \times h_{i, z}\right]}{\sum_{z=1}^{Z} \sum_{i=1}^{N_{o c c}(z)} h_{i, z}}$

Where $\mathrm{z}$ is zone counter, $\mathrm{i}$ is occupied hour counter, $\mathrm{Z}$ is total building zones, $\mathrm{N}_{\mathrm{occ}}(\mathrm{z})$ is the total number of zonal occupied hours, $\mathrm{T}_{\mathrm{op}, \mathrm{i}, \mathrm{z}}$ is the indoor operative temperature in zone $\mathrm{z}$ at time step $\mathrm{i}\left[{ }^{\circ} \mathrm{C}\right], \mathrm{T}_{\mathrm{op}, \mathrm{i}, \mathrm{z}, \mathrm{upper}}$ is the maximum comfort threshold in zone $\mathrm{z}$ at time step $\mathrm{i}\left[{ }^{\circ} \mathrm{C}\right]$, and $h$ is the time step [ $1 \mathrm{~h}]$. Only positive values of the difference $\left(\mathrm{T}_{\mathrm{op}, \mathrm{i}, \mathrm{z}}-\mathrm{T}_{\mathrm{op}, \mathrm{i}, \mathrm{z}, \mathrm{upper}}\right)^{+}$are considered. Both static and adaptive temperature limits can be used as comfort thresholds. The authors recommended two types of comfort models, (i) the static comfort model of CIBSE Guide A [75], and (ii) the adaptive comfort models by [76,77].

The $I O D$ is an asymmetric and multi-zonal index that allows for considering the occupancy profiles of each zone, separately. Such an approach makes it easier to use zone-specific comfort models to reflect the occupant behaviour and adaptation opportunities within a zone. However, it is only based on operative temperature and thus neglects the influential personal factors (i.e., clothing factor and metabolic rate) and environmental parameters (i.e., relative humidity and air velocity) in the determination of thermal comfort. Another drawback is that there are no threshold values recommended to limit the short-term and long-term overheating.

The second index is the Ambient Warmness Degree $\left(A W D_{b}\right)$ that shows the severity of outdoor thermal conditions. The $A W D_{b}\left[{ }^{\circ} \mathrm{C}\right]$ consists of averaging the cooling Degree hours over the total number of building occupied hours,

$A W D_{b}=\frac{\sum_{i=1}^{N}\left[\left(T_{a, i}-T_{b}\right)^{+} \times h_{i}\right]}{\sum_{i=1}^{N} h}$

Where $\mathrm{T}_{a}$ is the outdoor dry-bulb air temperature $\left[{ }^{\circ} \mathrm{C}\right], \mathrm{T}_{\mathrm{b}}$ is the base temperature $\left[{ }^{\circ} \mathrm{C}\right], \mathrm{N}$ is the total number of occupied hours when $T_{a, i} \geqslant T_{b}$. The choice of base temperature is context-specific depending on the climate and building characteristics (e.g., age, construction type, occupancy type etc.). The $\mathrm{T}_{\mathrm{b}}$ of $18^{\circ} \mathrm{C}$ is suggested by the authors appropriate for temperate climates. The main drawback regarding the calculation of the $A W D_{b}$ index is that it does not include the effect of solar radiation on outdoor thermal severity. It raises uncertainty since the same $A W D_{b}$ values result in two climates that have the same outdoor air temperature profiles but with different profiles of solar irradiance.

The $A W D_{b}$ was established and normalized by building occupied hours to be coupled with the IOD index through the dimensionless third index $\left(\alpha_{I O D / A W D}\right)$. Basically, the $\left(\alpha_{I O D / A W D}\right)$ index couples the indoor and outdoor thermal environments showing the sensitivity of a building to outdoor thermal stress. The $\left(\alpha_{\text {IOD/AWD }}\right)[-]$ is calculated by,

$\alpha_{I O D / A W D}=\frac{I O D}{A W D_{b}}$

$\alpha_{\mathrm{IOD} / \mathrm{AWD}}>1$ means that the building is unable to suppress outdoor thermal stress. $\alpha_{\mathrm{IOD} / \mathrm{AWD}}<1$ means that the building can suppress some of the outdoor thermal stress. It is suggested that the $I O D$ and $A W D_{b}$ indices be calculated under multiple contemporary and future weather scenarios. Afterwards, by assuming a linear regression between both parameters, one can calculate the $\alpha_{I O D / A W D}$. In this case, the $\alpha_{I O D / A W D}$ shows the sensitivity of a building to the progressive rise in outdoor air temperature due to the impact of climate change.

3.2.3.2. Heat exposure index (HEI). Hendel et al. [43] suggested Heat Exposure Index (HEI) which is a cumulative index focusing on overheating discomfort during sleeping time. The HEI index is resulted by integrating the difference between the indoor air temperature $\mathrm{T}_{a, \mathrm{i}}\left[{ }^{\circ} \mathrm{C}\right]$ and a set-point temperature $T_{\text {set-point }}\left[{ }^{\circ} \mathrm{C}\right]$ over the sleeping time (11 pm-7am). Only the positive values of the difference $\left(\mathrm{T}_{a, \mathrm{i}}-\mathrm{T}_{\text {set-point }}\right)^{+}$is considered. The HEI is calculated by,

$H E I=\int_{11 p m}^{7 a m}\left(T_{a, i}-T_{\text {set-point }}\right)^{+} T_{a, i \geq T_{\text {set-point }}} d t$

A set-point temperature of $26^{\circ} \mathrm{C}$ is suggested by the authors based on the work of [78]. The HEI is an asymmetric index focusing on overheating during sleeping time. It incorporates the intensity and the length of time when the indoor air temperature is exceeding the set-point temperature. The calculation method is not index-specific, and other indices such as the Universal Thermal Climate Index (UTCI) can be used instead of air temperature.

The HEI index has some limitations such as: (i) it makes a rough estimation regarding the sleeping time and duration, (ii) the threshold selection is contentious considering the threshold of $24^{\circ} \mathrm{C}$ suggested by WHO for bedrooms, (iii) it neglects the day-time overheating periods (iv) it does not consider other influential environmental parameters (i.e., radiant temperature, relative humidity, air velocity) and personal factors (i.e., metabolic rate and clothing factor) in the determination of thermal comfort, (v) it is not normalized to the occupied hours, and (vi) it is specific for short-term overheating evaluation and no threshold value is prescribed.

\section{Discussion}

This paper initially reviews the static and adaptive comfort models suggested by different standards to derive the threshold values in $P M V / P P D$ or operative temperature scales to be implemented in the overheating/discomfort calculations. Numerous studies discussed the applicability of the static and adaptive comfort models in buildings with different cooling modes (airconditioned, non-air-conditioned, and mixed-mode) [79-87]. It was reported in [88-90] that the static comfort models are performing well in air-conditioned spaces. However, such models overestimate the discomfort and technically predict more heating or cooling loads to provide a thermally comfortable environment [91]. On the other hand, the adaptive comfort models are 
suggested for naturally ventilated ones where the occupants have more connection to the outdoor environment [33,92]. Although there is still no consensus on the choice of comfort model in mixed-mode buildings, it was shown by Parkinson et al. [92] that these buildings are more closely aligned to naturally ventilated buildings in determining the neutral temperatures, and thus the adaptive comfort model is preferable.

It worth mentioning that the concept of occupant adaptation is more elaborated in thermally asymmetrical environments through the thermoregulatory models of the human body. Cheng et al. [34] reviewed such models and grouped them into physiological and psychological models. Thermoregulatory models deal with the whole or segmented human body interaction with the adjacent portion of the thermal environment. Therefore, they require detailed modelling (via numerical methods such as Computational Fluid Dynamics) or extensive point-in-space measurements to accurately reveal the distribution of environmental parameters (e.g., relative humidity, temperature etc.) through space. Two main factors are preventing their widespread, (i) there is a complexity associated with the detailed analysis of the thermal environment and segmentation of the human body, and (ii) they are environment-specific (i.e., sensitive to hot or cold environments) and thus not comprehensive enough [34].

Despite all the research into thermal comfort, there are still questions about the appropriateness of using it as a framework for assessing the issues such as morbidity and mortality [93,94]. The findings of [93] outline the lack of sufficient and direct epidemiological evidence concerning the adverse health effects due to high-temperature exposure. Whereas the mortality rate is increased during extreme events (e.g., heat waves) are positively associated with mortality. In addition, there is a lack of true understanding in the existing thermal comfort models when it comes to the most vulnerable population like the elderly people [42,95]. As a result, further research into thermal comfort and its effect on morbidity and mortality rate is required to solidify our understanding and instigate the policy changes.

Our review on time-integrated overheating indices led to significant findings in this context. We found that some indices such as Percentage of Occupied hours Outside the Range (\%POhOR $R_{E N}$ \& ISO 17772 and \%POhOR $I S O$ 7730), Averaged PPD (AvgPPD), PPD Over Time (PPDOT), Exceedance Hours (EH), and Weighted Exceedance Hours $(W E H)$ are symmetric. It means that they synthesize both overheating discomfort and overcooling discomfort in a single value. Although such indices provide useful insights on general comfort conditions in buildings, but they mix up two very different aspects of thermal comfort. Therefore, the sole use of these indices does not imply whether the building can overcome the overheating discomfort or overcooling discomfort.

Through our review, we attempt to distinguish between the criteria prescribed to limit short-term (hourly, daily, and weekly) and long-term (monthly, seasonal, and annual) overheating or discomfort. To ensure an acceptable thermal environment throughout the year, it is necessary to consider both short-term and long-term overheating criteria in building design and retrofit strategies. A building only complying with the short-term overheating criteria will be able to suppress the short-term heatwave events but might not be able to maintain an acceptable thermal environment in the long-term (i.e., design for heatwave). Differently, a building complying with only the long-term overheating criteria will be able to maintain an acceptable thermal environment in the long-term but might not be able to withstand short-term heatwave events (i.e., design for climate).

Surprisingly, none of the previous studies as well as ASHRAE 55 and ISO 7730 standards prescribed any threshold values. EN 15251 and Passive House standards provide a single value to limit only the long-term annual discomfort and overheating, respectively.
While more recent standards such as EN 16798 and ISO 17772 prescribe values to limit short-term (only weekly) and long-term (monthly and annual) discomfort in buildings. The CIBSE TM52 provides criteria to limit seasonal overheating as well as daily and instant overheating in naturally ventilated buildings. The EPBD regulations define annual criterion in Belgium, annual and seasonal criteria in Germany, annual criterion in France, monthly criterion in the UK, and monthly (only for July) criterion in the Netherlands. It shows that setting comprehensive criteria to fully limit shortterm and long-term overheating (or discomfort) phenomena was not so far that much of interest in building design and operation policies.

The building experts commonly agree that there is a growing risk of overheating in buildings due to the impact of climate change. The only study that examined overheating in the context of climate change is the work of Hamdy et al. [14] (see Section 3.2.3.1). They introduced the overheating escalation factor $\left(\alpha_{I O D / A W D}\right)$ index by coupling the Indoor Overheating (IOD) and Ambient Warmness Degree (AWD) indices. The IOD/AWD seems a promising index by integrating the rate of change in intensity and frequency of overheating in relation to the progressive rise in outdoor air temperature. In other words, it estimates the thermal sensitivity of a building to the overheating impact of climate change. A reliable value calculated for the IOD/AWD index allows the building designer to simply predict the evolution of overheating risks without requiring a whole building thermal modelling. It is also a useful index to compare the effectiveness of different active and passive cooling technologies on the thermal resistivity of buildings against the overheating impact of climate change.

\section{Conclusion}

In this paper, we have comprehensively reviewed the timeintegrated overheating/discomfort evaluation methods proposed for residential buildings in temperate climates in terms of thermal comfort models, indices, and criteria. We explored EN 15251, EN 16798, ISO 7730, ISO 17772, ASHRAE 55 (2017), ASHRAE 55 (2020), CIBSE Guide A (2006), CIBSE TM52, CIBSE Guide A (2015), CIBSE TM59, and Passive House standards (Section 3.2.1). We also look into five national building codes based on the Energy Performance of Building Directive (EPBD) in Belgium, France, Germany, the UK, and the Netherlands (Section 3.2.2) as well as two studies found in the scientific literature (Section 3.2.3). To summarize the significant recommendations and future research ideas, we provide the list below:

- In line with most standards, we suggest the static comfort models for air-conditioned buildings (see Table 2 and Table 3) and the adaptive comfort models for non-air-conditioned buildings both in living areas (see Table 4). The provisions are required in the bedrooms not to exceed the maximum threshold of $24{ }^{\circ} \mathrm{C}$ suggested by the WHO.

- We recommend using the asymmetric indices to detect the shortcomings of the building thermal design in the matter of overheating and overcooling discomfort, individually.

- We recommend considering full criteria for overheating (i.e., short-term and long-term) in building designs. This prevents overheating not only during a specific period (e.g., heatwave events), but also warm discomfort throughout the year.

- We recommend further exploring and validating the climate change-sensitive method based on three indices IOD, AWD, and $\alpha_{I O D / A W D}$ by applying them on real multizonal buildings. Future research can also go in the direction of developing climate-change sensitive overheating evaluation methods. 
- Future research is suggested to introduce time-integrated overheating indices by including more and more comfort parameters (i.e., relative humidity, metabolic rate, air velocity, air temperature, radiant temperature, and clothing factor). The new indices should be normalized to the occupied hours enabling a fair comparison between the buildings with different occupancy profiles.

- Future research is also recommended to review the overheating evaluation methods in non-residential buildings and in other climatic zones. Future research can analyze overheating calculation methods in the EPBD regulatory documents in other EU Member States.

Last but not least, the study is restricted to two major limitations. First, our review was limited to the methods and criteria proposed for overheating evaluations in residential buildings in temperate climates. Second, our study lacks the comparison and validation of the time-integrated overheating evaluation methods in a quantitative manner.

\section{Declaration of Competing Interest}

The authors declare that they have no known competing financial interests or personal relationships that could have appeared to influence the work reported in this paper.

\section{Acknowledgement}

This research was funded by the Walloon Region under the call 'Actions de Recherche Concertées 2019 (ARC)' (funding number:
ARC 19/23-05) and the project OCCuPANt, on the Impacts Of Climate Change on the indoor environmental and energy PerformAnce of buildiNgs in Belgium during summer. The authors would like to gratefully acknowledge the Walloon Region and the University of Liege for funding. We would like to also acknowledge the Sustainable Building Design (SBD) lab at the Faculty of Applied Sciences at the University of Liege for valuable support during the content analysis and curation of the data. This study is a part of the International Energy Agency (IEA) EBC Annex 80 - "Resilient cooling of buildings" project activities to define resilient cooling in residential buildings.

\section{Appendix A}

Table A.1 contains the origin and a short description of the international standards analyzed in this paper. These standards are widely adopted in temperate regions of Europe to assess the indoor environmental quality, in particular thermal comfort during the design and operation of residential buildings.

\section{Appendix B}

ISO and EN establish categories to define the static and adaptive comfort models reflecting the level of occupant expectation and indoor environmental quality. Similarly, ASHRAE 55 sets two ranges of acceptability $80 \%$ and $90 \%$ when defining the adaptive comfort model. The comfort categories are summarized in Table B.1.

Table A1

General description of comfort standards.

\begin{tabular}{|c|c|c|}
\hline Standards & Origin & Description \\
\hline EN 15251 and EN 16798 & $\begin{array}{l}\text { European (based in } \\
\text { Brussels, Belgium) }\end{array}$ & $\begin{array}{l}\text { EN } 15251 \text { was prepared by the Comité Européen de Normalisation (CEN) in } 2006 \text { as an essential } \\
\text { requirement to EU Directive } 2002 / 91 / E C \text { on Energy Performance of Building Directive (EPBD) } \\
\text { covering both residential and non-residential buildings. In 2019, the CEN published EN 16798-1 } \\
\text { and EN } 16798-2 \text {, replacing the parts of EN } 15,251 \text { related to indoor environmental input } \\
\text { parameters including the criteria for thermal comfort. EN } 16798-1 \text { contains the thermal comfort } \\
\text { models and EN } 16798-2 \text { contains the methods for time-integrated discomfort assessment. All } \\
\text { the above documents are still in force. }\end{array}$ \\
\hline ISO 7730 and ISO 17772 & $\begin{array}{l}\text { International (based in } \\
\text { Geneva, Switzerland) }\end{array}$ & $\begin{array}{l}\text { ISO (International Organization for Standardization) is a worldwide federation of national } \\
\text { standard bodies that published ISO } 7730 \text { in } 2004 \text { containing the ergonomics of thermal } \\
\text { environment and still remains in action. The ISO also published ISO } 17772-1 \text { in } 2017 \text { and ISO } \\
17772-2 \text { in } 2018 \text { defining indoor environmental quality and overall energy performance } \\
\text { assessments, respectively. ISO } 17772-1 \text { contains the thermal comfort models and ISO } 17772-2 \\
\text { contains the methods for time-integrated discomfort assessment. }\end{array}$ \\
\hline ASHRAE 55 (2017) and ASHRAE 55 (2020) & United States & $\begin{array}{l}\text { ASHRAE } 55 \text { (2017) was published in } 2017 \text { by the American Society of Heating, Ventilation, and } \\
\text { Air-conditioning Engineers (ASHRAE) containing thermal environmental conditions for human } \\
\text { occupancy in all building types. The ASHRAE } 55 \text { specifies the acceptable conditions for thermal } \\
\text { environments during the design, operation, and commissioning of occupied spaces. The latest } \\
\text { version of ASHRAE } 55 \text { was recently published in } 2020 \text {, with some minor changes superseding } \\
\text { the version } 2017 \text {. }\end{array}$ \\
\hline $\begin{array}{l}\text { CIBSE Guide A (2006), CIBSE TM52, CIBSE } \\
\text { Guide A (2015), and CIBSE TM59 }\end{array}$ & UK & $\begin{array}{l}\text { CIBSE Guide A was published in } 2006 \text { by Charted Institution of Building Services Engineering } \\
\text { (CIBSE), which is a standard setter and authority on building services as the primary UK } \\
\text { technical reference for the designers and installers of Heating, Ventilation, and Air-Conditioning } \\
\text { (HVAC) systems. Due to the increased risk of overheating, CIBSE formed an overheating task } \\
\text { force to define and address the overheating risks in buildings. The outcome of this overheating } \\
\text { task force activities was published as CIBSE TM52 in } 2013 \text {. Subsequently, a newer version of } \\
\text { CIBSE Guide A was published in 2015, superseding the version } 2006 \text { with some changes and } \\
\text { included the overheating criteria developed in CIBSE TM52 for naturally ventilated buildings. } \\
\text { CIBSE TM59 was also published in } 2017 \text { to provide a design methodology for the assessment of } \\
\text { overheating risk in homes. All the above documents, except CIBSE Guide A (2006), are still in } \\
\text { force. }\end{array}$ \\
\hline Passive House & Germany & $\begin{array}{l}\text { The Passive House is a voluntary standard provided by Passive House Institute (PHI) defining } \\
\text { complete criteria for indoor environmental quality and energy efficiency in buildings. The } \\
\text { Passive House standard aims at achieving a comfortable environment year-round with very low } \\
\text { energy consumption. The evidence of compliance with the Passive House standard must be } \\
\text { provided through a design tool called "Passive House Planning Package (PHPP)". }\end{array}$ \\
\hline
\end{tabular}


Table B1

Comfort category applicability in EN, ISO and ASHRAE.

\begin{tabular}{|c|c|c|}
\hline ISO 7730 Cat. & EN 15251, EN 16798, and ISO 17772 Cat. & Category description \\
\hline A & I & $\begin{array}{l}\text { High level of expectation recommended for spaces occupied by very fragile and sensitive } \\
\text { persons with special requirements such as handicapped, sick, very young children and elderly persons }\end{array}$ \\
\hline B & II & Normal level of expectation recommended for new buildings and renovations \\
\hline \multirow[t]{3}{*}{$\mathrm{C}$} & III & Moderate level of expectation suggested for existing buildings \\
\hline & IV (EN 16798) & Low level of expectation that compromises the comfort but not the occupants' health \\
\hline & IV (EN 15251) & Out-of-range values acceptable for limited periods \\
\hline \multicolumn{3}{|c|}{ ASHRAE 55 Cat. } \\
\hline \multicolumn{2}{|c|}{$90 \%$ acceptability } & When higher standard of thermal comfort is desired \\
\hline \multicolumn{2}{|c|}{$80 \%$ acceptability } & For typical applications \\
\hline
\end{tabular}

\section{References}

[1] J. Garssen, C. Harmsen, J. De Beer. The effect of the summer 2003 heat wave on mortality in the Netherlands, Eurosurveillance 10(7) 2005 13SP 557-14, 10.2807/esm.10.07.00557-en.

[2] M. Perry, N. Golding. Range of environmental temperature conditions in the United Kingdom, Met Office, Department of Transport, Exeter, UK, 2011. [Online]. Available: https://www.onr.org.uk/transport/temperature-rangereport.pdf.

[3] P. Pirard et al., Summary of the mortality impact assessment of the 2003 heat wave in France, Eurosurveillance 10 (7) (2005) 7-8.

[4] A.H. Fink, T. Brücher, A. Krüger, G.C. Leckebusch, J.G. Pinto, U. Ulbrich, The 2003 European summer heatwaves and drought-synoptic diagnosis and impacts, Weather 59 (8) (2004) 209-216.

[5] B.E. Johansen, The encyclopedia of global warming science and technology, ABC-CLIO, Santa Barbara, California, 2009.

[6] M. Santamouris, Innovating to zero the building sector in Europe: Minimising the energy consumption, eradication of the energy poverty and mitigating the local climate change, Sol. Energy 128 (2016) 61-94, https://doi.org/10.1016/ j.solener.2016.01.021.

[7] M. Santamouris et al., Urban heat island and overheating characteristics in Sydney, Australia. An analysis of multiyear measurements, Sustainability 9 (5) (2017) 712, https://doi.org/10.3390/su9050712.

[8] T. Oke. The heat island of the urban boundary layer: characteristics, causes and effects, in Wind climate in cities, Springer, 1995, pp. 81-107.

[9] K. Oleson, Contrasts between urban and rural climate in CCSM4 CMIP5 climate change scenarios, J. Clim. 25 (5) (2012) 1390-1412, https://doi.org/10.1175/ JCLI-D-11-00098.1.

[10] A.-T. Nguyen, S. Reiter, P. Rigo, A review on simulation-based optimization methods applied to building performance analysis, Appl. Energy 113 (2014) 1043-1058, https://doi.org/10.1016/j.apenergy.2013.08.061Get, rights and content.

[11] E. Oikonomou, M. Davies, A. Mavrogianni, P. Biddulph, P. Wilkinson, M. Kolokotroni, Modelling the relative importance of the urban heat island and the thermal quality of dwellings for overheating in London, Build. Environ. 57 (2012) 223-238, https://doi.org/10.1016/j.buildenv.2012.04.002.

[12] A. Mavrogianni, A. Pathan, E. Oikonomou, P. Biddulph, P. Symonds, M. Davies, Inhabitant actions and summer overheating risk in London dwellings, Build. Res. Inf. 45 (1-2) (2017), https://doi.org/10.1080/09613218.2016.1208431.

[13] T. Psomas, P. Heiselberg, K. Duer, E. Bjørn, Overheating risk barriers to energy renovations of single family houses: multicriteria analysis and assessment, Energy Build. 117 (2016) 138-148, https://doi.org/10.1016/j. enbuild.2016.02.031.

[14] M. Hamdy, S. Carlucci, P.-J. Hoes, J.L.M. Hensen, The impact of climate change on the overheating risk in dwellings-A Dutch case study, Build. Environ. 122 (Sep. 2017) 307-323, https://doi.org/10.1016/j.buildenv.2017.06.031.

[15] P. Symonds et al., Overheating in English dwellings: comparing modelled and monitored large-scale datasets, Build. Res. Inf., 45(1-2) 2016 10.1080/ 09613218.2016 .1224675 .

[16] L. Lan, K. Tsuzuki, Y. Liu, Z. Lian, Thermal environment and sleep quality: a review, Energy Build. 149 (2017) 101-113, https://doi.org/10.1016/j. enbuild.2017.05.043Get.

[17] H. Hooyberghs, S. Verbeke, D. Lauwaet, H. Costa, G. Floater, K. De Ridder, Influence of climate change on summer cooling costs and heat stress in urban office buildings, Clim. Change 144 (4) (2017) 721-735, https://doi.org/ 10.1007/s10584-017-2058-1.

[18] HHSRS, "HHSRS Guidance for Landlords and Property-Related Professionals," London, UK, 2006. [Online]. Available: https://www.gov.uk/government/ publications/ housing-health-and-safety-rating-system-guidance-forlandlords-and-property-related-professionals.

[19] G. Brücker, Vulnerable populations: lessons learnt from the summer 2003 heat waves in Europe, Eurosurveillance 10 (7) (2005) 1-2, https://doi.org/10.2807/ esm.10.07.00551-en.

[20] A. Fouillet et al., Excess mortality related to the August 2003 heat wave in France, Int. Arch. Occup. Environ. Health 80 (1) (2006) 16-24, https://doi.org/ 10.1007/s00420-006-0089-4.
[21] H. Johnson, S. Kovats, G. McGregor, J. Stedman, M. Gibbs, H. Walton, The impact of the 2003 heat wave on daily mortality in England and Wales and the use of rapid weekly mortality estimates, Eurosurveillance 10 (7) (2005) 15-16, https://doi.org/10.2807/esm.10.07.00558-en.

[22] J.-M. Robine, S. L. Cheung, S. Le Roy, H. Van Oyen, F. R. Herrmann. Report on excess mortality in Europe during summer 2003, EU Community Action Programme Public Health Grant Agreem. 2005114200728.

[23] J.-M. Robine et al., Death toll exceeded 70,000 in Europe during the summer of 2003, C. R. Biol., 331(2) 2008 10.1016/j.crvi.2007.12.001.

[24] D. Enescu, A review of thermal comfort models and indicators for indoor environments, Renew. Sustain. Energy Rev. 79 (Nov. 2017) 1353-1379, https://doi.org/10.1016/j.rser.2017.05.175.

[25] EN 15251, EN 15251: Indoor environmental input parameters for design and assessment of energy performance of buildings addressing indoor air quality, thermal environment, lighting and acoustics. European Committee for Standardization, Brussels, Belgium, 2006.

[26] ISO 7730, ISO 7730: Ergonomics of the Thermal Environment. Analytical Determination and Interpretation of Thermal Comfort Using Calculation of the PMV and PPD Indices and Local Thermal Comfort Criteria. International Standards Organization Geneva, 2004.

[27] R.S. McLeod, M. Swainson, Chronic overheating in low carbon urban developments in a temperate climate, Renew. Sustain. Energy Rev. 74 (Jul. 2017) 201-220, https://doi.org/10.1016/j.rser.2016.09.106.

[28] ANSI/ASHRAE Standard 55, Standard 55-2017: Thermal Environmental Conditions for Human Occupancy. American Society of Heating, Refrigerating and Air Conditioning Engineers: Atlanta, GA, USA, 2017.

[29] S. Carlucci, L. Pagliano, A review of indices for the long-term evaluation of the general thermal comfort conditions in buildings, Energy Build. 53 (2012) 194205, https://doi.org/10.1016/j.enbuild.2012.06.015.

[30] M. Beshir, J.D. Ramsey, Heat stress indices: a review paper, Int. J. Ind. Ergon. 3 (2) (1988) 89-102.

[31] M. Taleghani, M. Tenpierik, S. Kurvers, A. van den Dobbelsteen, A review into thermal comfort in buildings, Renew. Sustain. Energy Rev. 26 (2013) 201-215, https://doi.org/10.1016/j.rser.2013.05.050.

[32] D. Khovalyg et al., "Critical review of standards for indoor thermal environment and air quality," Energy Build. 2020109819 10.1016/j. enbuild.2020.109819.

[33] S. Carlucci, L. Bai, R. de Dear, L. Yang, Review of adaptive thermal comfort models in built environmental regulatory documents, Build. Environ. 137 (2018) 73-89, https://doi.org/10.1016/j.buildenv.2018.03.053.

[34] Y. Cheng, J. Niu, N. Gao, Thermal comfort models: a review and numerical investigation, Int. Workshop Vent. Comf. Health Transp. Veh. 47 (2012) 13-22, https://doi.org/10.1016/j.buildenv.2011.05.011.

[35] J. Van Hoof, M. Mazej, J.L. Hensen, Thermal comfort: research and practice, Front. Biosci. 15 (2) (2010) 765-788, https://doi.org/10.2741/3645.

[36] E. Halawa, J. van Hoof, The adaptive approach to thermal comfort: a critical overview, Energy Build. 51 (2012) 101-110, https://doi.org/10.1016/j. enbuild.2012.04.011.

[37] L. Yang, H. Yan, J.C. Lam, Thermal comfort and building energy consumption implications - A review, Appl. Energy 115 (2014) 164-173, https://doi.org/ 10.1016/j.apenergy.2013.10.062.

[38] Q. Zhao, Z. Lian, D. Lai, Thermal comfort models and their developments: a review, Energy Built Environ. 2 (1) (Jan. 2021) 21-33, https://doi.org/10.1016/ j.enbenv.2020.05.007.

[39] S. Roaf, F. Nicol, M. Humphreys, P. Tuohy, A. Boerstra, Twentieth century standards for thermal comfort: promoting high energy buildings, Archit. Sci. Rev. 53 (1) (2010) 65-77, https://doi.org/10.3763/asre.2009.0111.

[40] S. Carlucci. Thermal comfort assessment of buildings, Springer, 2013, 10.1007/ 978-88-470-5238-3.

[41] Zero Carbon Hub, Impacts of Overheating: Evidence Review, Zero Carbon Hub, London, England, 2015.

[42] NHBC. Overheating in new homes: A review of the evidence, National HouseBuilding Council, UK., 2012.

[43] M. Hendel, K. Azos-Diaz, B. Tremeac, Behavioral adaptation to heat-related health risks in cities, Energy Build. 152 (2017) 823-829, https://doi.org/ 10.1016/j.enbuild.2016.11.063. 
[44] European Commission (EC), "Eurostat - Tables, Graphs and Maps Interface (TGM) table," 2017. Accessed: May 19, 2021. [Online]. Available: https://ec. europa.eu/eurostat/web/main/help/first-visit/tgm.

[45] R.S. Kovats, S. Hajat, Heat stress and public health: a critical review, Annu. Rev. Public Health 29 (1) (2008) 41-55, https://doi.org/10.1146/annurev. publhealth.29.020907.090843.

[46] K.J. Lomas, S.M. Porritt, Overheating in buildings: lessons from research, Build. Res. Inf. (2017), https://doi.org/10.1080/09613218.2017.1256136.

[47] S. Yannas, J. Rodríguez-Álvarez, Domestic overheating in a temperate climate: feedback from London Residential Schemes, Sustain. Cities Soc. 59 (2020), https://doi.org/10.1016/j.scs.2020.102189 102189.

[48] A. Mavrogianni et al., The impact of occupancy patterns, occupant-controlled ventilation and shading on indoor overheating risk in domestic environments, Build. Environ. 78 (2014) 183-198, https://doi.org/10.1016/j. buildenv.2014.04.008.

[49] T. Psomas, P. Heiselberg, K. Duer, M.M. Andersen. Comparison and statistical analysis of long-term overheating indices applied on energy renovated dwellings in temperate climates, Indoor Built Environ. 27(3) 2018 10.1177/ $1420326 X 16683435$.

[50] R. Birchmore, K. Davies, P. Etherington, R. Tait, A. Pivac. Overheating in Auckland homes: testing and interventions in full-scale and simulated houses, Build. Res. Inf. 45(1-2) 2016, 10.1080/09613218.2017.1232857.

[51] H. Elsharkawy, S. Zahiri, The significance of occupancy profiles in determining post retrofit indoor thermal comfort, overheating risk and building energy performance, Build. Environ. 172 (2020), https://doi.org/10.1016/j. buildenv.2020.106676 106676.

[52] M.J. Fletcher, D.K. Johnston, D.W. Glew, J.M. Parker, An empirical evaluation of temporal overheating in an assisted living Passivhaus dwelling in the UK, Build. Environ. 121 (2017) 106-118, https://doi.org/10.1016/j. buildenv.2017.05.024.

[53] A. Pathan, A. Mavrogianni, A. Summerfield, T. Oreszczyn, M. Davies, Monitoring summer indoor overheating in the London housing stock, Energy Build. 141 (2017) 361-378, https://doi.org/10.1016/j.enbuild.2017. 02.049 .

[54] M. Mulville, S. Stravoravdis, The impact of regulations on overheating risk in dwellings, Build. Res. Inf. 44 (5-6) (2016) Aug, https://doi.org/10.1080/ 09613218.2016 .1153355

[55] W.V. Lee, K. Steemers. Exposure duration in overheating assessments: a retrofit modelling study, Build. Res. Inf. 45(1-2) 2016, 10.1080/ 09613218.2017 .1252614$.

[56] L. Rodrigues, V. Sougkakis, M. Gillott. Investigating the potential of adding thermal mass to mitigate overheating in a super-insulated low-energy timber house, Int. J. Low-Carbon Technol. 11(3) 2016 10.1093/ijlct/ctv003.

[57] United Nations (UN), "World Population Prospects - Population Division"," United Nations. Accessed: May 19, 2021. [Online]. Available: https:// population.un.org/wpp/Download/Standard/Population/.

[58] United Nations (UN), "Demographic Yearbook - Table 3: Population by sex, rate of population increase, surface area and density," United Nations Statistics division, 2014. Accessed: May 19, 2021. [Online]. Available: http://unstats.un. org/unsd/demographic/products/dyb/dyb2012/Table03.pdf.

[59] R. De Vecchi, M.J. Sorgato, M. Pacheco, C. Cândido, R. Lamberts, ASHRAE 55 adaptive model application in hot and humid climates: the Brazilian case, Archit. Sci. Rev. 58 (1) (2015) 93-101, https://doi.org/10.1080/ 00038628.2014 .981145

[60] Y. Yuan, J. Shim, S. Lee, D. Song, J. Kim, Prediction for overheating risk based on deep learning in a zero energy building, Sustainability 12 (21) (2020) 8974, https://doi.org/10.3390/su12218974.

[61] E. Recast, Directive 2010/31/EU of the European Parliament and of the Council of 19 May 2010 on the energy performance of buildings (recast), Off. J. Eur. Union 18 (06) (2010) 2010.

[62] IBGE, "Performance Energétique des Bâtiments: Guide des exigences et des procédures de la réglementation Travaux PEB en Région de Bruxelles Capitale," Brussels, Belgium, 2017.

[63] Vlaams Energie- en Klimaatagentschap, Bijlage V Bepalingsmethode EPW: BEPALINGSMETHODE VAN HET PEIL VAN PRIMAIR ENERGIEVERBRUIK VAN RESIDENTIËLE EENHEDEN, Flanders, Belgium, 2020.

[64] Gouvernement Wallon, "Méthode PER 2018: MÉTHODE DE DÉTERMINATION DU NIVEAU DE CONSOMMATION D'ÉNERGIE PRIMAIRE DES UNITES RESIDENTIELLES," Wallonia, Belgium, 2018.

[65] V. Fux, "Thermische Gebäudesimulation zum sommerlichen Wärmeschutz nach DIN 4108-2: 2013,” Hochsch. Für Tech. Stuttg., 2013.

[66] U. Krone, F. Ascione, N. Bianco, T. Tschirner, O. Böttcher, Prescriptive-and performance-based approaches of the present and previous German DIN 4108-2. Hourly energy simulation for comparing the effectiveness of the methods, Energy Procedia 75 (2015) 1315-1324.

[67] Ministère de la transition écologique, "Réglementation environnementale RE2020," France, 2020.

[68] HM Government, "The Building Regulations 2010: Conservation of fuel and power in new dwellings, Approved Document L1A," 2013 edition incorporating 2016 amendments, UK.
[69] HM Government, "The Building Regulations 2010: Conservation of fuel and power in existing dwellings, Approved Document L1B," 2010 edition incorporating 2010, 2011, 2013. 2016, and 2018 amendments, UK.

[70] DCLG, "Housing Standards Review: Summary of Responses," Department for Communities and Local Government, London, UK, ISBN: 978-1-4098-4178-4 2014. [Online]. Available: https://www.gov. uk/government/consultations/housing-standards-review-consultation.

[71] HM Government, "The Building Regulations 2010: Conservation of fuel and power in new dwellings, Approved Document L1A," 2013 edition, UK.

[72] BRE (DECC), “SAP 2012: The Government's Standard Assessment Procedure for Energy Rating of Dwellings," Watford, UK, 2012.

[73] UK Government, "Approved Document [X] - Overheating." Jan. 2021. Accessed: Aug. 30, 2021. [Online]. Available: https://assets.publishing. service.gov.uk/government/uploads/system/uploads/attachment_data/file/ 953752/Draft_guidance_on_heating.pdf.

[74] NTA 8800, NTA 8800: Energieprestatie van gebouwen-Bepalingsmethode. Royal Netherlands Standardization Institute, Delft, Netherlands, 2019.

[75] BRE (DECC), "SAP 2012: The Government's Standard Assessment Procedure for Energy Rating of Dwellings," Watford, UK, 2012.

[76] I. I. Publicatie, "74; Thermische behaaglijkheid e eisen voor de binnentemperatuur in gebouwen, Stichting ISSO," Rotterdam Neth., 2004.

[77] A.C. van der Linden, A.C. Boerstra, A.K. Raue, S.R. Kurvers, R.J. de Dear, Adaptive temperature limits: a new guideline in The Netherlands: A new approach for the assessment of building performance with respect to thermal indoor climate, Energy Build. 38 (1) (2006) 8-17, https://doi.org/10.1016/j. enbuild.2005.02.008.

[78] N. Willand, I. Ridley, A. Pears, Relationship of thermal performance rating, summer indoor temperatures and cooling energy use in 107 homes in Melbourne, Australia, Energy Build. 113 (2016) 159-168, https://doi.org/ 10.1016/j.enbuild.2015.12.032.

[79] J.F. Nicol, I.A. Raja, A. Allaudin, G.N. Jamy, Climatic variations in comfortable temperatures: the Pakistan projects, Energy Build. 30 (3) (1999) 261-279, https://doi.org/10.1016/S0378-7788(99)00011-0.

[80] I. Fato, F. Martellotta, C. Chiancarella, Thermal comfort in the climatic conditions of Southern Italy, Trans.-Am. Soc. Heat. Refrig. AIR Cond. Eng. 110 (2) (2004) 578-593.

[81] R.J. De Dear, A. Auliciems, Validation of the predicted mean vote model of thermal comfort in six Australian field studies, ASHRAE Trans. 91 (2 B) (1985) $452-468$.

[82] G.E. Schiller, A comparison of measured and predicted comfort in office buildings, ASHRAE Trans. 96 (1) (1990) 609-622.

[83] J.F. Busch, Thermal responses to the Thai office environment, ASHRAE Trans. 96 (1) (1990) 859-872.

[84] J.F. Busch, A tale of two populations: thermal comfort in air-conditioned and naturally ventilated offices in Thailand, Energy Build. 18 (3) (1992) 235-249, https://doi.org/10.1016/0378-7788(92)90016-A.

[85] K. van der Linden, A.C. Boerstra, A.K. Raue, S.R. Kurvers, Thermal indoor climate building performance characterized by human comfort response, Energy Build. 34 (7) (2002) 737-744, https://doi.org/10.1016/S0378-7788(01)00144-X.

[86] S. Heidari, S. Sharples, A comparative analysis of short-term and long-term thermal comfort surveys in Iran, Energy Build. 34 (6) (2002) 607-614, https:/ doi.org/10.1016/S0378-7788(02)00011-7.

[87] N. Yamtraipat, J. Khedari, J. Hirunlabh, Thermal comfort standards for air conditioned buildings in hot and humid Thailand considering additional factors of acclimatization and education level, Sol. Energy 78 (4) (2005) 504517, https://doi.org/10.1016/j.solener.2004.07.006.

[88] R. De Dear and G. S. Brager, "Developing an adaptive model of thermal comfort and preference," UC Berkeley Cent. Built Environ., 1998, Accessed: Feb. 03 2020. [Online]. Available: https://escholarship.org/uc/item/4qq2p9c6.

[89] W.A. Andreasi, R. Lamberts, C. Cândido, Thermal acceptability assessment in buildings located in hot and humid regions in Brazil, Build. Environ. 45 (5) (2010) 1225-1232, https://doi.org/10.1016/j.buildenv.2009.11.005.

[90] P. Ole Fanger, J. Toftum. Extension of the PMV model to non-air-conditioned buildings in warm climates, Energy Build. 34(6) 2002 533-536 10.1016/ S0378-7788(02)00003-8.

[91] M.A. Humphreys, J. Fergus Nicol. The validity of ISO-PMV for predicting comfort votes in every-day thermal environments, Energy Build. 34(6) 2002 667-684 10.1016/S0378-7788(02)00018-X.

[92] T. Parkinson, R. de Dear, G. Brager, Nudging the adaptive thermal comfort model, Energy Build. 206 (2020), https://doi.org/10.1016/j. enbuild.2019.109559 109559.

[93] R. Basu, J.M. Samet, Relation between elevated ambient temperature and mortality: a review of the epidemiologic evidence, Epidemiol. Rev. 24 (2) (2002) 190-202, https://doi.org/10.1093/epirev/mxf007.

[94] B.R. Hughes, H.N. Chaudhry, S.A. Ghani, A review of sustainable cooling technologies in buildings, Renew. Sustain. Energy Rev. 15 (6) (2011) 3112 3120, https://doi.org/10.1016/j.rser.2011.03.032.

[95] C. Hughes, S. Natarajan, Summer thermal comfort and overheating in the elderly, Build. Serv. Eng. Res. Technol. 40 (4) (2019) 426-445, https://doi.org/ $10.1177 / 0143624419844518$. 